\title{
InSAR Reveals Land Deformation at Guangzhou and Foshan, China between 2011 and 2017 with COSMO-SkyMed Data
}

\author{
Alex Hay-Man Ng ${ }^{1,2} \mathbb{( D}^{(}$, Hua Wang ${ }^{1, *}$, Yiwei Dai ${ }^{1}$, Carolina Pagli ${ }^{3}$, Wenbin Chen ${ }^{1}$, Linlin Ge ${ }^{2}$, \\ Zheyuan $\mathrm{Du}^{2}$ and Kui Zhang ${ }^{4}$ \\ 1 Department of Surveying Engineering, Guangdong University of Technology, Guangzhou 510006, China; \\ hayman.ng@gmail.com (A.H.-M.N.); ywdai1026@163.com (Y.D.); wbchen0418@foxmail.com (W.C.) \\ 2 School of Civil and Environmental Engineering, UNSW Australia, Sydney 2052, Australia; \\ l.ge@unsw.edu.au (L.G.); z.du@unsw.edu.au (Z.D.) \\ 3 Department of Earth Sciences, University of Pisa, Pisa 56100, Italy; carolina.pagli@unipi.it \\ 4 School of Communication Engineering, Chongqing University, Chongqing 400044, China; zk@cqu.edu.cn \\ * Correspondence: ehwang@163.com; Tel.: +86-135-7001-9257
}

Received: 23 April 2018; Accepted: 23 May 2018; Published: 24 May 2018

check for updates

\begin{abstract}
Subsidence from groundwater extraction and underground tunnel excavation has been known for more than a decade in Guangzhou and Foshan, but past studies have only monitored the subsidence patterns as far as 2011 using InSAR. In this study, the deformation occurring during the most recent time-period between 2011 and 2017 has been measured using COSMO-SkyMed (CSK) to understand if changes in temporal and spatial patterns of subsidence rates occurred. Using InSAR time-series analysis (TS-InSAR), we found that significant surface displacement rates occurred in the study area varying from $-35 \mathrm{~mm} /$ year (subsidence) to $10 \mathrm{~mm} /$ year (uplift). The 2011-2017 TS-InSAR results were compared to two separate TS-InSAR analyses (2011-2013, and 2013-2017). Our CSK TS-InSAR results are in broad agreement with previous ENVISAT results and levelling data, strengthening our conclusion that localised subsidence phenomena occurs at different locations in Guangzhou and Foshan. A comparison between temporal and spatial patterns of deformations from our TS-InSAR measurements and different land use types in Guangzhou shows that there is no clear relationship between them. Many local scale deformation zones have been identified related to different phenomena. The majority of deformations is related to excessive groundwater extraction for agricultural and industrial purposes but subsidence in areas of subway construction also occurred. Furthermore, a detailed analysis on the sinkhole collapse in early 2018 has been conducted, suggesting that surface loading may be a controlling factor of the subsidence, especially along the road and highway. Roads and highways with similar subsidence phenomenon are identified. Continuous monitoring of the deforming areas identified by our analysis is important to measure the magnitude and spatial pattern of the evolving deformations in order to minimise the risk and hazards of land subsidence.
\end{abstract}

Keywords: subsidence; Persistent Scatterer Interferometry; TS-InSAR; Guangzhou; Foshan

\section{Introduction}

Many large deltas in the world have been experiencing subsidence because of soil consolidation and compaction, water extraction, and underground tunnelling driven by the rapid economic and population growth $[1,2]$. These deltas accommodate a large percentage of the human population, hence, significant subsidence can cause serious problems to buildings and infrastructures, generating tension cracks. Moreover, deltas are low-lying plains where even small ground subsidence can 
significantly increase the risk of flood hazards and seawater intrusion. Therefore, continuous and accurate monitoring of ground subsidence at the major cities in these deltas is crucial to assess the level of risk.

The Greater Pearl River Delta (GPRD) is one of the main hubs of China's economic growth; it is also one of the largest urban agglomerations and fastest-growing urban regions of the world and is located on alluvial and lacustrine deposits. In this study, the land stability of Guangzhou and Foshan, two of the main mega-cities in the GPRD, are investigated. The studied area was built over a network of canals in the Pearl River flood plain. The majority of the man-made infrastructures in the study area are less than one metre above sea level (area with white colour in Figure 1). Subsidence in Guangzhou and Foshan has occurred for many years, mainly caused by sediment loading and compaction, and groundwater extraction due to concentrated urban development [3-5]. For example, tens of buildings in Jinshazhou at Guangzhou were damaged by the subsidence caused by underground construction of the high-speed railway underground project, resulting in an economic loss of 30 million RMB (currency of People's Republic of China) [6]. In addition, the development in these areas is much faster than its drainage infrastructure could support. This, together with the continually increasing sea level rise and ground subsidence, puts the local population under a greater risk of environmental problems, such as flooding and saltwater intrusion. In recent years, Guangzhou has frequently suffered from urban flooding. On 7 May 2010 and 31 March 2014, extreme rainfall caused inundations and severe transport chaos [7]. The frequent flooding and ground collapses in Guangzhou have also caused huge economic losses and endangered the lives of citizens $[4,6,8]$. Systematic analysis of the land subsidence in Guangzhou and its neighbour, Foshan, is, therefore, required for subsidence risk assessment and mitigation.

The capability of InSAR for land deformation mapping has already been demonstrated in many applications, for example surface displacements monitoring during and after tunnels excavations [9-11], and groundwater exploitation [12,13]. The radar interferometry time-series technique (TS-InSAR), an extension of the conventional InSAR technique, has been used for mapping surface deformation for many years [14-18], because it is capable of obtaining accurate measurements of surface deformation rates over large areas and at high spatial and temporal resolutions. TS-InSAR is also much more cost-effective than conventional ground-based surveying techniques [19-24].

Subsidence events in Guangzhou and Foshan between 2006 and 2011 have been well studied using TS-InSAR techniques. Zhao et al. [25] utilised $10 \mathrm{C}$-band ENVISAT ASAR images acquired between 2007 and 2008 to measure the subsidence in Guangzhou, and showed that the maximum subsidence rate was $-26 \mathrm{~mm}$ /year. Wang, et al. [26] demonstrated that most of the region in Guangzhou and Foshan was stable between 2006 and 2009 based on the TS-InSAR result from 19 ENVISAT ASAR images. Zhao, Lin, and Jiang [25] suggested that the subsidence was caused by brittle hydrogeological failures and underground excavations. Chen, Lin, Zhang, and Lu [6] analysed the ENVISAT ASAR data acquired between 2006 and 2010 and concluded that anthropogenic activities, such as subway construction and groundwater extraction, should be primarily responsible for the local subsidence. Wanget al. [5] conducted a study using both ENVISAT ASAR and L-band ALOS PALSAR data and found that the newly excavated subway tunnels (Lines 2, 3, 6 and GuangFo) correspond to areas subsiding at an average rate of more than $-8 \mathrm{~mm} /$ year between 2007 and 2011. They suggested that the maximum subsidence along the GuangFo line ranged from $-5.2 \mathrm{~mm}$ to $-23.6 \mathrm{~mm}$ and its ground loss ratio ranged from $1.5 \%$ to $8.7 \%$ between 2008 and 2011 . These studies have provided information about the patterns of subsidence that are useful to improve the urban planning in Guangzhou.

This study aims to investigate the deformation in Guangzhou and Foshan between 2011 and 2017 using X-band COSMO-SkyMed (CSK) SAR data, which can provide much higher resolution than the C-band Envisat and L-band ALOS satellites previously used in the region. More importantly, the previous studies focused on the subsidence period between 2006 and 2011, the comprehensive subsidence phenomenon at Guangzhou and Foshan is not known after 2011. It is worth noting that significant developments in the subway system in Foshan and Guangzhou have been implemented 
since 2011. Foshan and Guangzhou have up to 10 metro lines covering a total length of $309 \mathrm{~km}$ and 167 stations as of August 2017, which is a large jump from the length of $250.8 \mathrm{~km}$ and 153 stations at the end of 2011. The subsidence is one aspect connected to the rapid urban development in Guangzhou and Foshan, which may lead to serious economic loss and threaten human life. Hence, up-to-date subsidence information is very important because it is useful for assessing the risk of subsidence-related incidents that may occur in the near future.
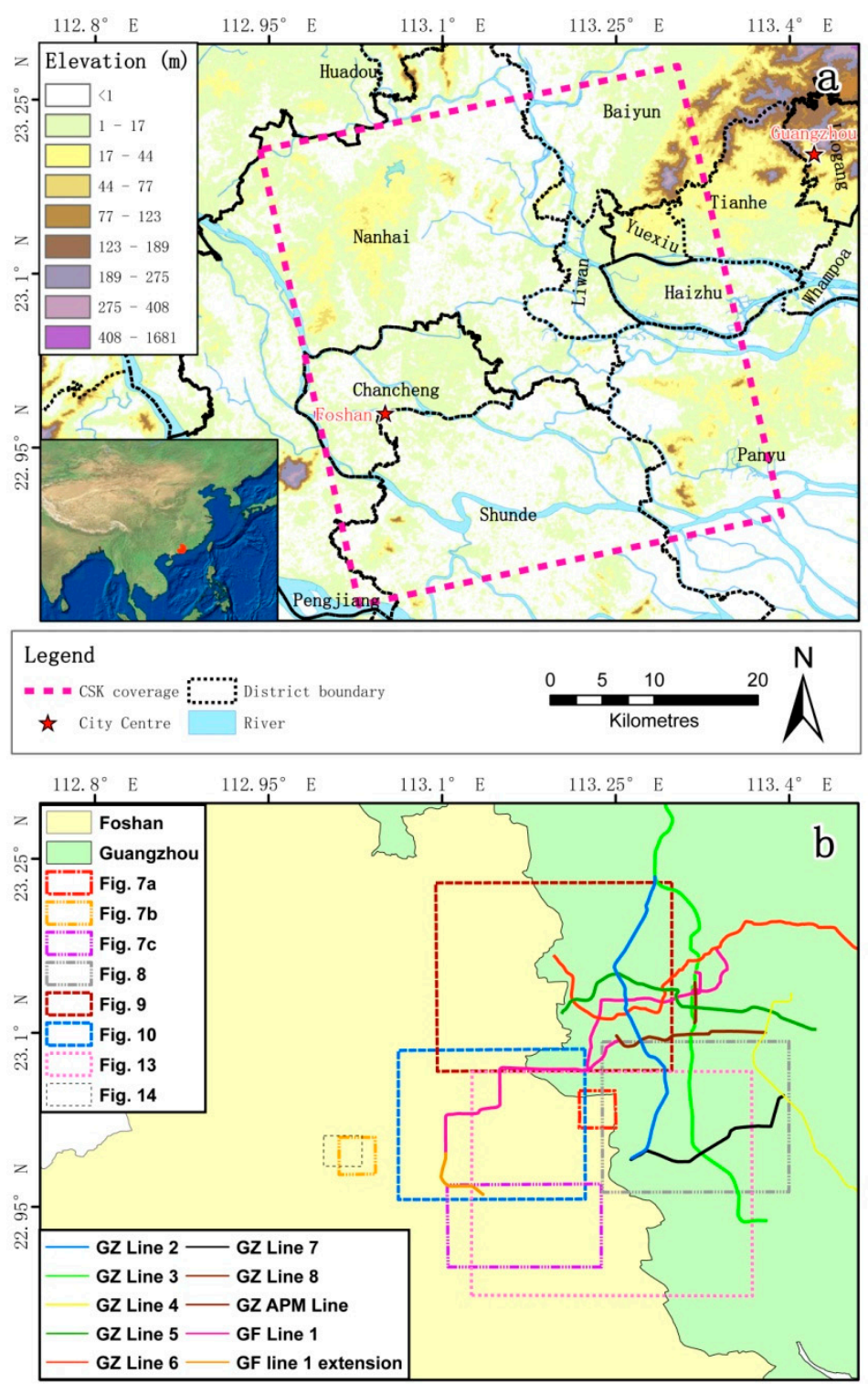

Figure 1. (a) SRTM (Shuttle Radar Topography Mission) digital elevation model of the study area. The white colour represents the flood-prone area (elevation lower than $1 \mathrm{~m}$ ); and (b) the 10 subway lines in Guangzhou and Foshan, and the selected areas for detailed analysis.

A number of researchers have already demonstrated that the up-to-date displacement information obtained from SAR data can be useful for detecting the rapidly developing surface deformations such as in areas subject to collapse. Nof, et al. [27] demonstrated that CSK data can be used to detect the precursory subsidence occurring a few months before sinkhole collapse in Israel. Chang and Hanssen [28] analysed the SAR data between 1992 and 2011 at a shopping mall in Heerlen, the Netherlands and showed a dramatic increase in vertical deformation in the last few years preceding the sinkhole formation. 
The authors then argued that early detection of sinkhole deformations potentially leading to collapses is possible using InSAR monitoring. Therefore, recent subsidence data at Guangzhou and Foshan is very important for assessing the risk of future sinkholes formation, in particular as a sinkhole formed in Foshan on 7 February 2018, which resulted in the deaths of eight people.

\section{Study Area}

Guangzhou and Foshan are located in a humid subtropical climate zone controlled by the Asian monsoon, characterised by wet summers with high temperatures and high humidity and cool dry winters. The mean annual temperature is around $22-23{ }^{\circ} \mathrm{C}$. The annual rainfall is about $1700 \mathrm{~mm}$. The lengthy monsoon season, with average monthly rainfall between 166 and $284 \mathrm{~mm}$, spans from April through September, during which the cities frequently experience floods.

The landform of the study area is relatively flat (Figure 1), with altitudes of most area less than $50 \mathrm{~m}$. Guangzhou is located in the Guangdong Depression Belt of the South China fold system. There are more than 40 faults and 30 folds. The boundary of the tectonic depression is marked by two active faults, the Guang-Cong Fault and the Guang-San Fault [29]. The two faults have divided Guangzhou into three geological units: the Zengcheng Hilly area, the Guanghua Basin area, and the Southern Plain area. According to the Guangdong Geological Bureau reports [4,5,29], there are three geological formations, i.e., soft, loose deposits, buried karst, and other types of bedrock in this area. The first two geological units are subject to subsidence, thereby threatening the safety of the surrounding buildings. The bedrock consists of different types of granite [30] widespread throughout the Zengcheng Hilly area and the northern Guanghua Basin. The weathered granitic gneiss is very sensitive to moisture alternation and has complex geotechnical characteristics that create difficulties during construction and, hence, significantly limit the progress of the urban development.

The northern and western portions of Guangzhou city are built over limestone terrains, where rock corrosion by fluid circulation with fracture formations and the karst caves develop [4]. A high rate of annual rainfall can favour ground collapse in the karst areas. The collapse of karst-cave roofs is common during the rainy season due to enhanced dissolution when the underground water table rises and the water flow rate increases. The karst-cave roofs can also collapse because of the overburden following the rainy season when the underground water table drains.

\section{Dataset and Methodology}

\subsection{Dataset}

In this study, we analysed 86 X-band CSK HIMAGE SAR images in stripmap mode collected from 20 May 2011 to 27 January 2017 over the study area. The CSK images are acquired in ascending orbits with spatial resolution of $3 \mathrm{~m}$ in both range and azimuth. Based on previous studies [4,26], most of the surface deformation in the study area are expected to be focused on relatively small areas with a radius of a few kilometres and with a magnitude of the deformation of less than $\sim 20 \mathrm{~mm} /$ year. Another focus of this paper is to study the urban areas of Guangzhou and Foshan where the temporal decorrelation is not an issue compared to areas with dense vegetation cover. X-band SAR products, which are sensitive to small deformations, are, hence, the preferred choice rather than C-band and L-band SAR data. The reference image acquired on 9 June 2013 was chosen as it minimises the perpendicular and temporal baselines of the series of interferograms (Figure 2). The perpendicular baseline varies between $-1069 \mathrm{~m}$ and $1317 \mathrm{~m}$ and the time-period of observations spans 2079 days (approximately 5.7 years). 


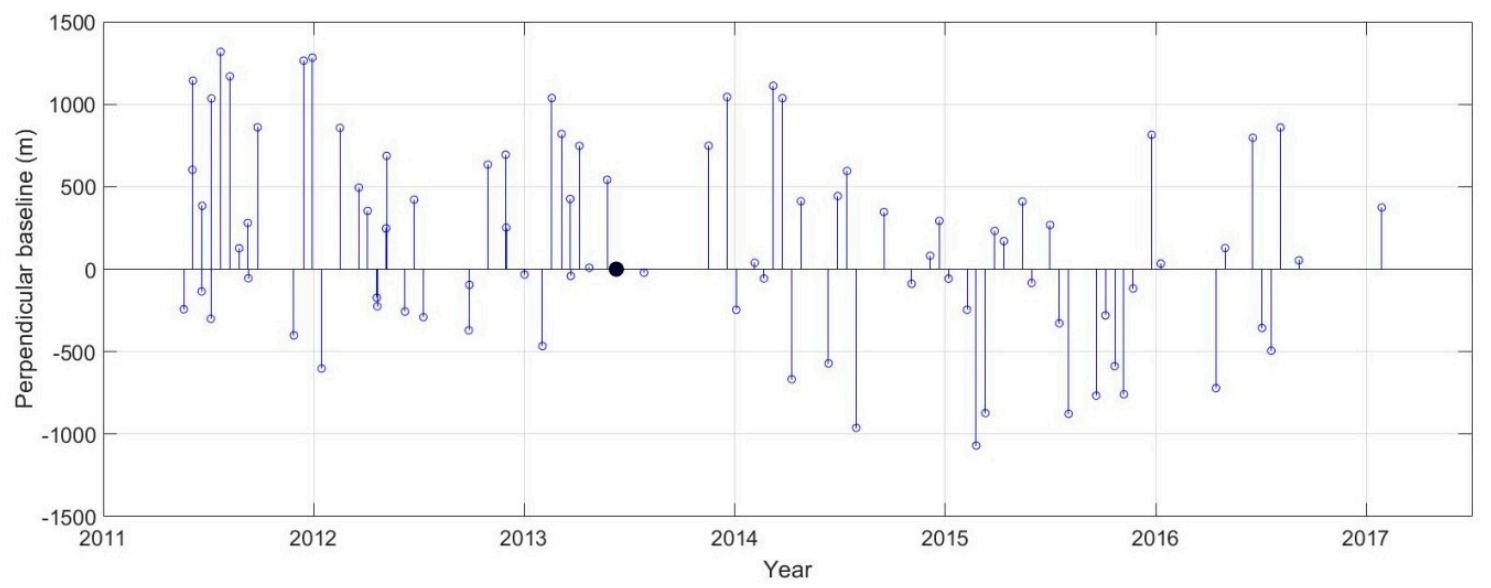

Figure 2. CSK SAR dataset (orbit direction: ascending; imaging mode: HIMAGE; polarisation: HH; incidence angle: $29.5^{\circ}$; look direction: right). The black solid circle at zero perpendicular baseline represents the master image.

\subsection{Methodology}

In this study, TS-InSAR analysis is conducted in order to derive the deformation times-series from the multi-temporal CSK SAR data. The TS-InSAR software, GEOS-ATSA (Advance Time-Series Analysis), is used. GEOS-ATSA, the extension of GEOS-PSI, is a software developed in the GEOS group at the University of New South Wales for InSAR time-series analysis which has been proven to be an efficient and reliable tool for mapping land deformation [20,21,31]. The single master approach mode is chosen [15], in which 85 differential interferograms are generated with respect to the selected master image acquired on 9 June 2013. The differential interferograms are generated using the conventional two-pass differential InSAR method [32,33], where the topographic phase components are removed using the one arc-second Shuttle Radar Topography Mission (SRTM) digital elevation model (DEM) [34].

After generating the interferograms, the coherent distributed scatterer (DS) and persistent scatterer (PS) selection process is conducted. For DS selection, the DeSpecKS algorithm is used to reduce the speckle and decorrelation noise over the statistically homogeneous areas [14]. The phase linking algorithm [35] is then applied to estimate the optimal phase value of the DS at each acquisition. Only the pixels that pass the goodness-of-fit test $(\gamma>0.4)$ are retained for further processing [14]. For PS selection, all pixels with amplitude dispersion index $\left(D_{A}\right)$ lower than 0.25 are selected [15].

A reference triangular network is then constructed based on the reliable DS $(\gamma>0.65)$ and PS $\left(D_{A}<0.25\right)$ with a maximum arc length of $1.5 \mathrm{~km}$. The modelled parameters (i.e., deformation and topographic error) are then computed using the approach discussed in $\mathrm{Ng}$ et al. [31]. Due to the large amount of data available, a more relaxing ensemble phase coherence threshold can be used to assess if the estimated parameters fit the modelled parameters [36]. The estimated data with ensemble phase coherence higher than 0.6 are used for further analysis. The modelled parameters of the isolated DS $(\gamma>0.4)$ and PS $\left(D_{A}<0.25\right)$ are estimated from the parameters of the reference network using the adaptive estimation strategy [31].

The TS-InSAR measurements are relative to a reference point/area, which is often chosen in a stable point/area. Unfortunately, ground truth measurements are not available to us to identify a stable point. However, previous studies in this area $[4,5,26]$ have shown that the subsidence in this region is localised to small areas. Therefore, we assumed that the broad region is stable and we fixed a virtual reference point rather than a fixed point/area. We initially selected our reference point in an area that is believed to have no deformation (black diamond in Figure 3) $[4,5,26]$. We obtained the displacement rate map for each pixel relative to the selected reference point, then we calculated the mode of the displacement rates and we recalculated all our maps relative to this value. The mode is 
used here instead of the mean or median in order to avoid the bias due to the local-scale subsidence (Figure 4). If a reference point, or a virtual point from a small area, is used, there is a possibility that the reference point/area may correspond to a previously unknown ground subsidence zone. This potential limitation is overcome by this method of selecting a virtual reference point based on the displacement rate distribution in the broad region.
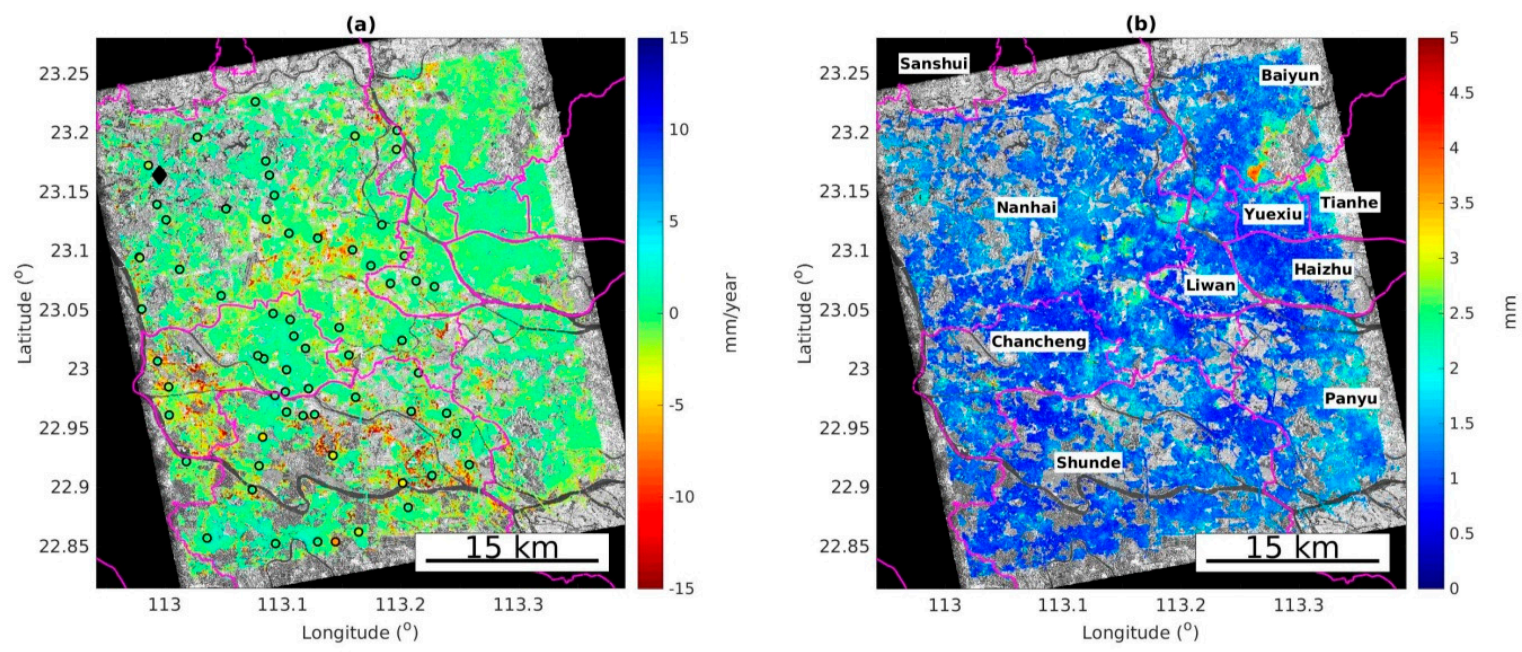

Figure 3. (a) CSK subsidence rates (2011-2017) and (b) their standard deviations for Guangzhou and Foshan overlaid on the average intensity image. The levelling derived mean subsidence rate at 63 benchmarks between 2005 and 2012 are highlighted by the black circles. The same colour bar is used for the subsidence rate of both measurements. The negative sign in the figure indicates subsidence, while the positive sign indicates uplift. The purple lines represent the district boundary. The black diamond sign indicates the reference points used to compare with the levelling and ENVISAT measurements.

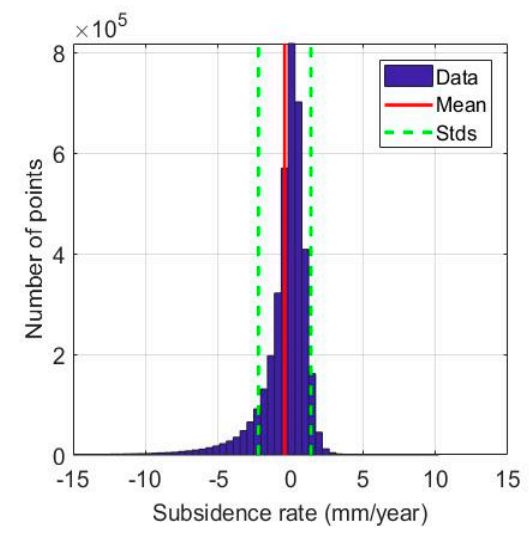

(a)

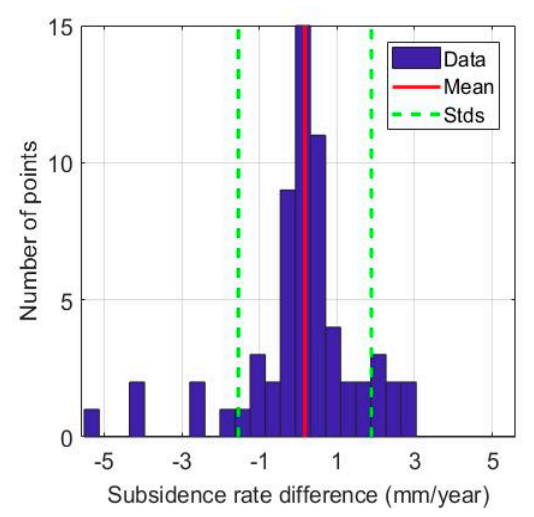

(b)

Figure 4. The distribution of (a) the InSAR-derived subsidence rate and (b) the subsidence rate difference between the CSK and the levelling measurements.

A hybrid atmospheric model is assumed here, whereby the atmospheric artefacts are assumed to be made up of two components: topography-related and non-topography-related artefacts. These two components are estimated separately based on the approach used in $\mathrm{Ng}$ et al. [37]. Finally, the non-linear displacement components of the DS and PS are estimated using the residual phase after the corrections of modelled parameters, atmospheric signals, and orbit signals. The displacement 
time-series are derived by combining the linear displacement component and the non-linear displacement component.

Displacements are measured by SAR along the radar line-of-sight (LoS) direction, therefore, measurements from multiple viewing geometries are needed to derive the displacements in vertical, easting, and northing directions $[23,38]$. However, since only the images from the CSK ascending orbit are used in this paper, and given that the dominant deformation in Guangzhou and Foshan is expected to be in the vertical direction $[4,5]$, the displacement observed in the LoS direction is directly projected onto vertical direction with the assumption of zero horizontal displacements.

\section{InSAR Results}

The subsidence rate map generated using CSK data is shown in Figure 3. The total number of pixels (i.e., DS and PS pixels) is 3,772,305, corresponding to a pixel density of approximately 2441 pixels $/ \mathrm{km}^{2}$. The distribution of subsidence displacement rates with a mean of $-0.4 \mathrm{~mm} /$ year and standard deviation of $1.8 \mathrm{~mm} /$ year is shown in Figure 4a. The subsidence rates range from $-35 \mathrm{~mm} /$ year (subsidence) to $10 \mathrm{~mm} /$ year (uplift). The subsidence areas are mainly found in the south and southwest directions, where no clear uplift is observed. The subsidence rate at approximately $99.7 \%$ of the measurement points is between $-15 \mathrm{~mm}$ /year to $15 \mathrm{~mm}$ /year.

The pixels are evenly distributed $\left(\sim 3800\right.$ points $\left./ \mathrm{km}^{2}\right)$ in the central part of the map mainly because coherence is kept in the dense urban areas. Relatively sparse pixels $\left(\sim 2150\right.$ points $\left./ \mathrm{km}^{2}\right)$ are obtained in the northern and southern parts of the study area, because of vegetation cover outside the main urban areas, causing some decorrelation.

The levelling data obtained between 2005 and 2012 are compared to the CSK-derived subsidence rates to investigate whether the assumption that most areas in the region are stable in time is correct. The levelling data from [26] is used for the comparison. The levelling data was collected in three campaigns with 105, 8 and 113 surveying benchmarks in 2005, 2009 and 2012, respectively, within the CSK coverage. The subsidence rate at each benchmark is computed with relative to the earlier campaign. The levelling data show that most of the area is stable between 2005 and 2012 with a mean subsidence rate of $0.6 \mathrm{~mm} /$ year and a standard deviation of $1.7 \mathrm{~mm} /$ year. Although the temporal overlap between the measurements is not perfect, it can be expected that most areas that were stable between 2005 and 2012 would remain stable between 2011 and 2017, assuming that no sudden deformations started since 2012 and that the two measurements agree well with each other. A quantitative analysis of the differences between subsidence rates obtained from both measurements is performed. It is worth noting that the TS-InSAR measurement points (MPs) and levelling benchmarks are often at different locations. In order to match the identified MPs and the benchmarks, the following procedure is applied: (1) a grid with spatial resolution of $30 \mathrm{~m} \times 30 \mathrm{~m}$ is created; (2) the location of the MPs corresponding to the grid is assigned; (3) the location of the benchmarks corresponding to the grid is identified; (4) multiple MPs within the same grid cell are assumed to be representative of the same deformation signal, hence, the displacement values within each cell are calculated by averaging all the MPs corresponding to the grid cell; (5) common pixels between the measurements are identified; and (6) a reference point is selected from one of the common pixels (see Figure 3) and the relative subsidence rate at each common pixel with respect to the reference point is calculated. There are 63 benchmarks considered as common pixels after the above procedure, while the remaining levelling benchmarks are either located near the edge of the CSK boundary or in the area with low coherence (i.e., no measurement points nearby). The subsidence rate at the 63 levelling benchmarks from [26] is overlaid on the CSK-derived subsidence rate map (circle with black outline in Figure 3). The histogram of the subsidence rate difference between the two measurements is shown in Figure $4 \mathrm{~b}$. It can be seen that the two sets of measurements are in good agreement with a mean difference of $0.2 \mathrm{~mm} /$ year and standard deviation of $1.7 \mathrm{~mm} /$ year.

Two separate TS-InSAR analyses are conducted using the CSK images acquired between 2011 and 2013 (45 images), and those acquired from 2013 to 2017 (42 images). The two results are compared 
to investigate the temporal behaviour of the subsidence in Guangzhou and Foshan. The subsidence rate maps for the first and second sets are shown in Figure 5. The results show that the displacement pattern and magnitude of the three displacement maps (2011-2017, 2011-2013, and 2013-2017) are in broad agreement. However, a number of areas, which appears to deform at different rates, are observed, including areas such as the centre and southern part of Nanhai district, the western part of Chancheng district, the northern part of Shunde district, and the southwest part of Haizhu. For example, the southern part of Nanhai district at Foshan appears to be deforming in Figure 5a, but it is relatively stable in Figure $5 b$. Figure 6 shows the deformation time series of a point in this area. Rapid deformation, over $-11.3 \mathrm{~mm}$ /year, occurred between 2011 and mid-2012, but waned after mid-2012, suggesting that such an area is not affected by stable, linear subsidence (see discussion for further detail). Interestingly, the temporal variation of displacement rates observed in regions characterised by subsidence may be the result of the rapid urban developments and sudden, episodic changes in the groundwater level.

The CSK measurements are compared to the ENVISAT measurements, which were generated based on 19 ENVISAT ASAR images acquired between 2006 and 2009 [26]. Since the spatial resolution of CSK and ENVISAT data is different, the CSK result is resampled at the same grid spacing as the ENVISAT result for comparison. The comparison procedure here is similar to the approach used for the levelling data. The reference point is selected in the same area (Figure 3), but a grid with a spatial resolution of $90 \mathrm{~m} \times 90 \mathrm{~m}$ is used instead. There are 106,511 common points after the above procedure. Figure 7 shows a broad agreement between the CSK and ENVISAT subsidence rate maps with a mean subsidence difference of $0.1 \mathrm{~mm} /$ year and standard deviation of $1.8 \mathrm{~mm} /$ year between the two measurements.
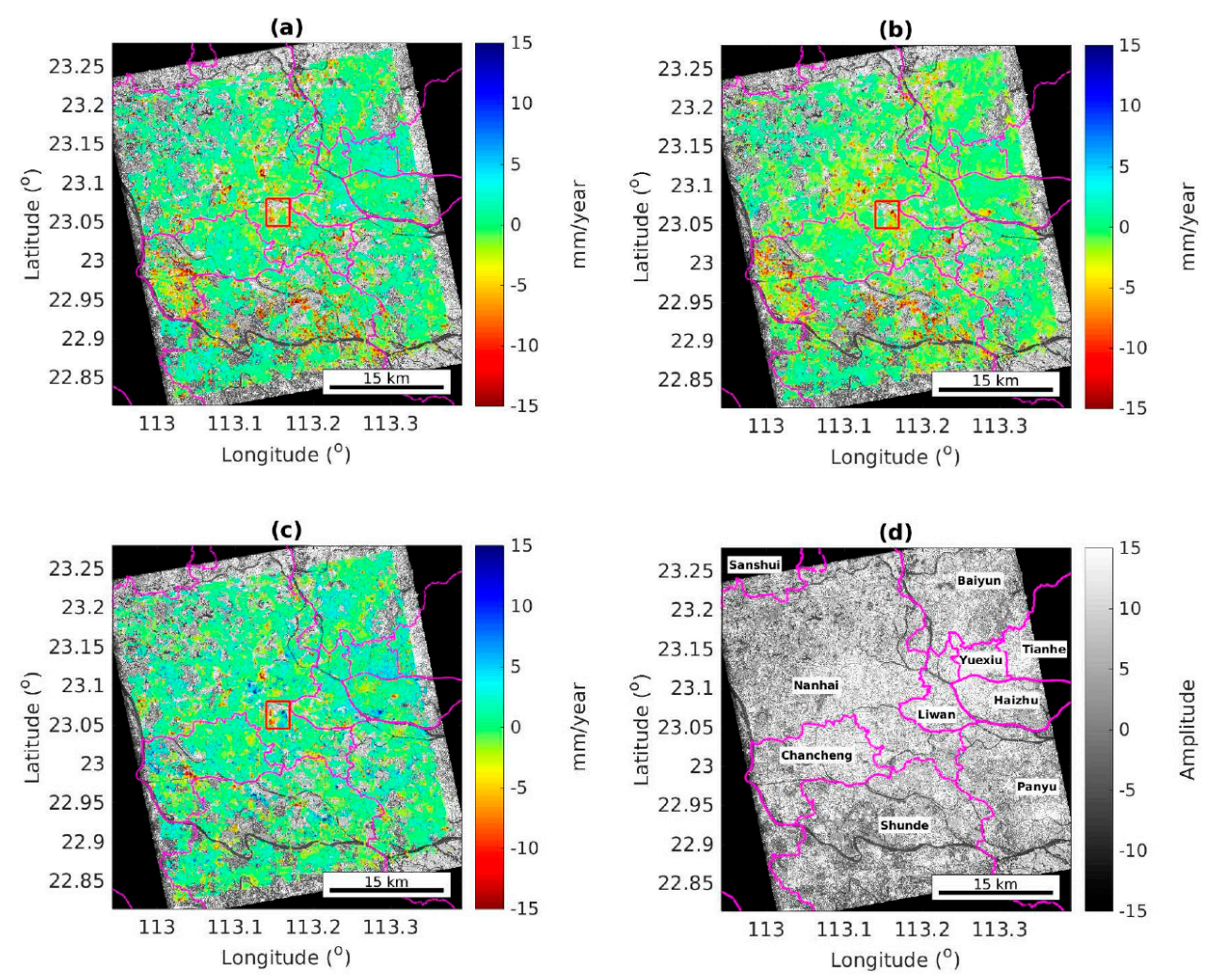

Figure 5. CSK subsidence rate maps from (a) 2011-2013 and (b) 2013-2017 for Guangzhou and Foshan overlaid on the average intensity image; (c) The difference in subsidence rate between (a) and (b). The blue colour represents increased in subsidence, and the red colour indicates the subsidence has eased. The red rectangle highlighted one of the areas with large difference in subsidence rate as an example; and (d) district information overlaid on the CSK average intensity map. 


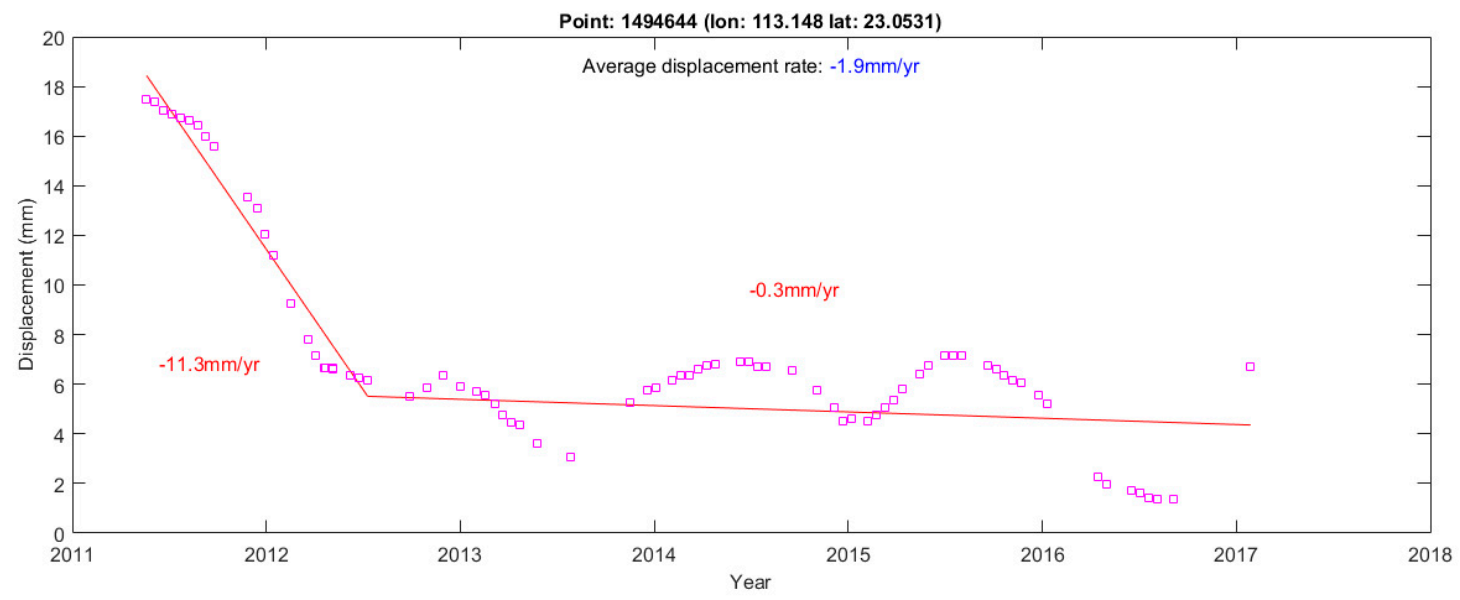

Figure 6. InSAR-measured displacement series at the area in Nanhai district.
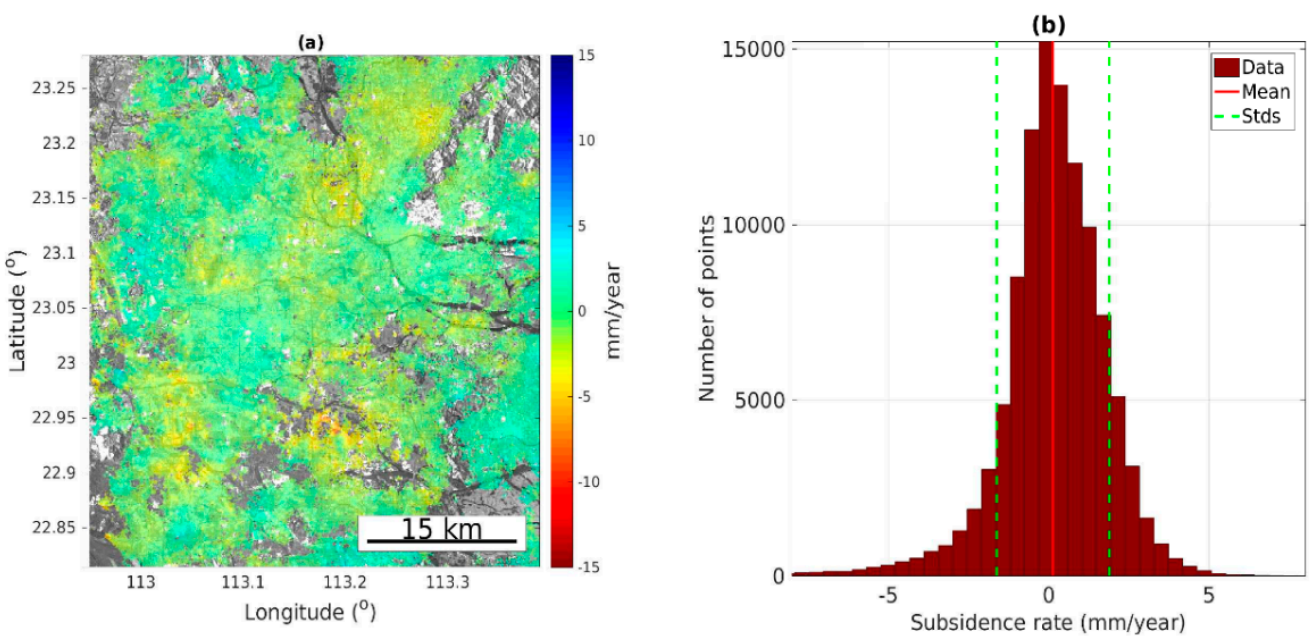

Figure 7. (a) ENVISAT ASAR subsidence rate map (2006-2009) for Guangzhou and Foshan overlaid on the average intensity image (generated using the TS-InSAR results from Wang, Yu, and Jiang [26]); and (b) subsidence rate difference between the CSK and the ENVISAT measurements at the common pixels.

\section{Discussion}

\subsection{General Land Displacement Pattern and Evolution}

The TS-InSAR results show similar patterns in Figures 3 and 5, indicating that most deforming areas are experiencing continuous subsidence over the six-year period from 2011 to 2017. Moreover, the general agreement between the CSK subsidence rate map (2011-2017) and ENVISAT ASAR subsidence rate map (2006-2009) also indicate that most deformations have been ongoing at least since 2006. Subsidence rates from different time periods are similar in most of these actively deforming areas, suggesting that many of the areas are deforming at approximately constant rates.

Apart from the two regional scale land zones in the south and south-west part of the study area, most deformation phenomena observed in this study are local. The deformation zones identified by this study are mainly in the western part of Panyu district, the southern part of Haizhu district, and the western part of Liwan district in Guangzhou, and the western part of Chancheng district, Beijiao town (northern part of Shunde district), and the eastern part of Nanhai district in Foshan (see Figures 1 and 3). 


\subsection{Groundwater Subsidence}

According to $\mathrm{Xu}$ [39], there are over 6000 groundwater wells in Foshan, and many of them extract waters from shallow aquifers, at depths of only $\sim 5 \mathrm{~m}$ from the surface. Moreover, illegal groundwater extractions are very common in industrial areas [39]. A similar scenario is expected in Guangzhou. Therefore, groundwater extraction is expected to be one of the main causes of subsidence in Foshan and Guangzhou.

The groundwater subsidence phenomena found in Guangzhou and Foshan are very different from those identified in other large cities such as Beijing (China) and Bandung (Indonesia). Groundwater over-extraction in those cities has led to subsidence over large spatial scales (tens of kilometres) $[19,21,31]$ while many, but focused, deformation patterns of approximately a few kilometres radius have been observed in Guangzhou and Foshan. The groundwater withdrawal in the Beijing area is mainly at depths of 20-200 $\mathrm{m}[40,41]$, whereas the groundwater abstraction with depth ranges from $40-60 \mathrm{~m}$ are common for domestic use [42]. Therefore, one explanation is that the depth of the exploited aquifers in Guangzhou and Foshan are shallow, hence, the relatively narrow extent of the deformation zones.

Figure 8 shows areas of subsidence that are possibly caused by groundwater exploitation. The rapidly deforming region in Figure 8a is located at Sanshan Yidong Industrial Zone at Nanhai District where subsidence rates of up to $-23 \mathrm{~mm}$ /year are observed. The industrial zone is dense with factories of different types, including factories for moulds, toy, footwear, metalware, etc. These factories typically require large amount of water during the production cycle and it is, therefore, likely that the observed subsidence is related to groundwater pumping. Figure $8 \mathrm{~b}$ shows subsidence over an ecological farm at Chancheng District with deformation rates of up to $-30 \mathrm{~mm} /$ year around the farm. Since groundwater is commonly used for irrigation purposes, subsidence from groundwater exploitation is likely occurring in this area. The subsidence rate of Beijiao Township in the Northern Shunde District, is a well-known signal [26] (Figure 8c). The peak deformation rate observed here is $-21 \mathrm{~mm} /$ year, which is only slightly lower than at the other two places. Although the deformation rate is lower, the spatial extent of the signal is the largest. Moreover, this region is a combination of agricultural, residential, and industrial developments. Considering many vegetated areas in this township where no measurement points could be obtained, it can be concluded that the maximum subsidence rate could be many times larger than the reported here. Possible causes of the subsidence in Beijiao include groundwater extraction, lack of bearing capacity in the buildings foundations, and the unstable geological conditions.

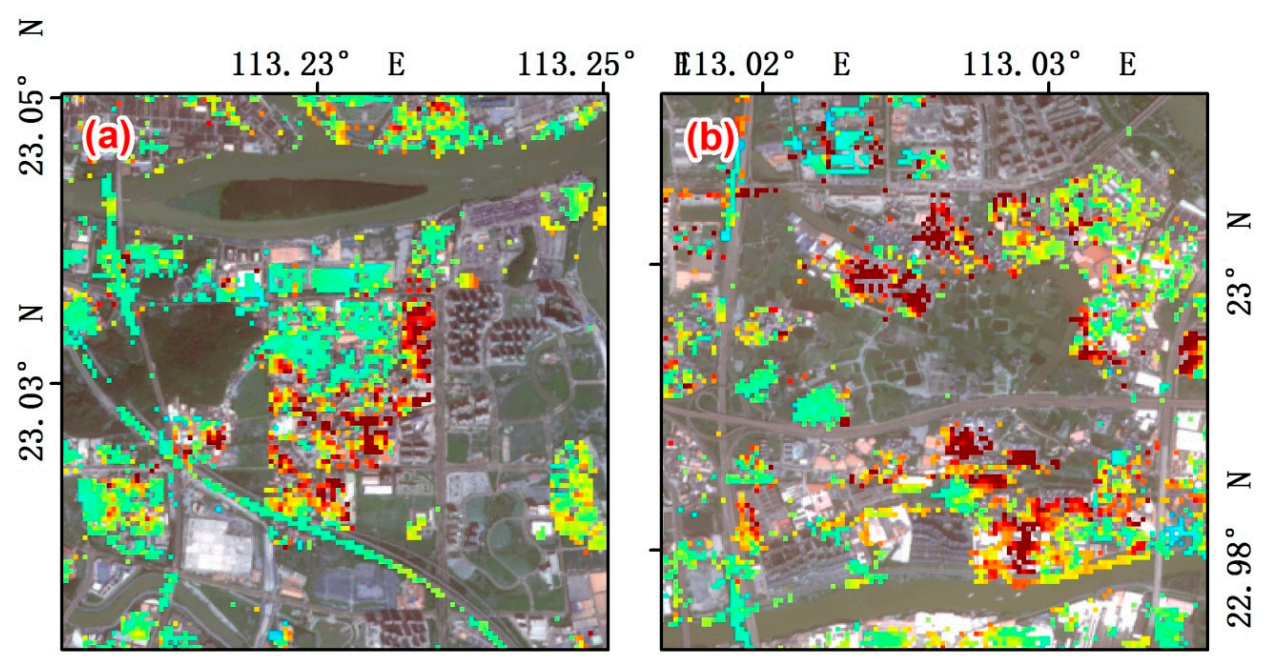

Figure 8. Cont. 


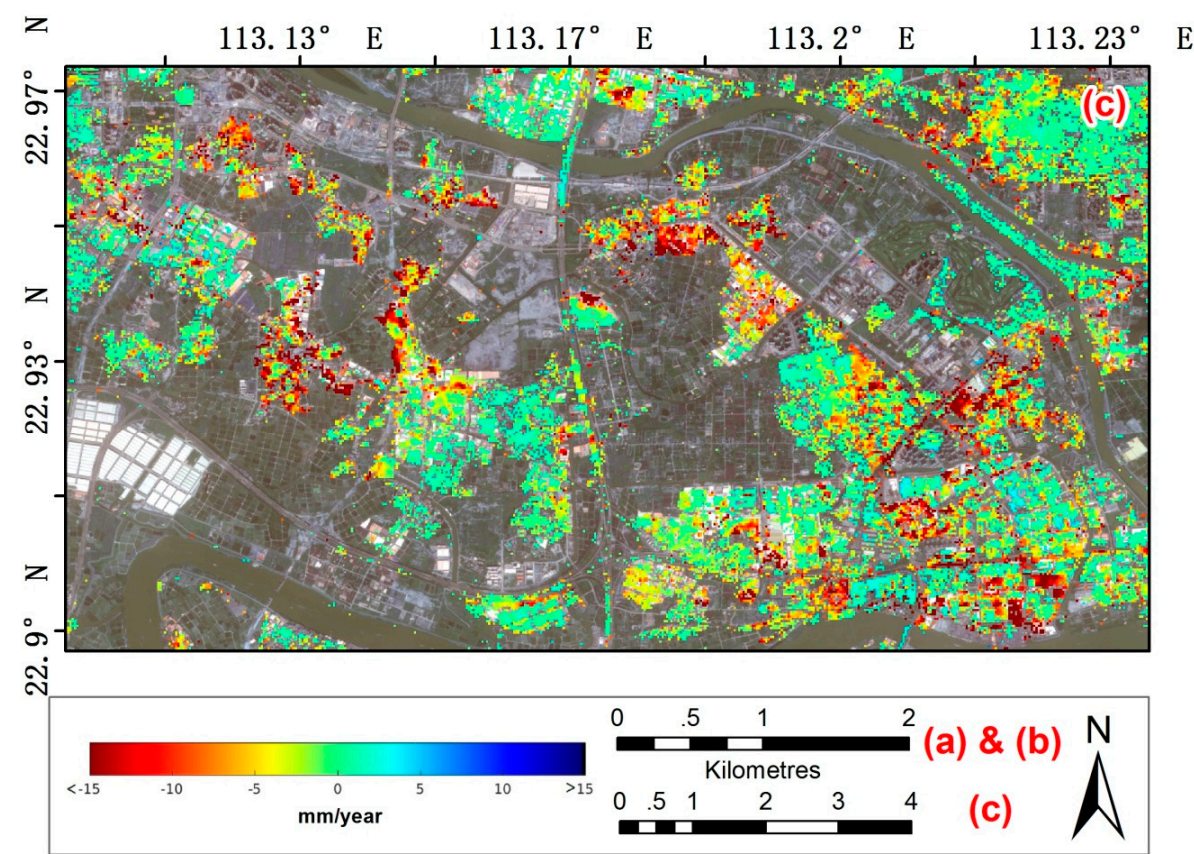

Figure 8. InSAR-measured displacement rate map between 2011 and 2017 at possible groundwater subsidence areas. (a) Sanshan Yidong Industrial Zone at Nanhai District; (b) Pengcheng new village ecological farm at Chancheng District; and (c) Beijiao Township in Northern Shunde District. These areas are located at point 1, 2 and 3, respectively in Figure 1. The background images are the Sentinel-2 true colour images acquired on 1 November 2017.

\subsection{Subsidence Observed along the Subway/Railway Lines}

The surface subsidence caused by tunnel excavation during subway construction has been reported between 2006 and 2011 [4,5,29]. Although some of these subsidence phenomena can still be observed in the CSK results, many of the previously-identified subsidence zones do not appear in the CSK result, especially for the Guangzhou (GZ) Subway Line 1, 5, 8, and APM (Zhujiang New Town Automated People Mover System), likely because most of the subway lines in Guangzhou were already completed and operational before 2011.

A number of subway lines have been constructed between 2011 and 2017, including the GZ Line 7 and the extensions of the GuangFo (GF) Line 1 and GZ Line 6. This study is, hence, focused on these new subsidence patterns.

According to the news reported in March 2016, cracks in the buildings with gaps of approximately $1 \mathrm{~cm}$ were found near the Nanzhou station at GZ Line 2 [43]. Figure 9 shows that the subsidence near that location (highlighted by the red cross in the figure) is approximately $-8 \mathrm{~mm} /$ year. Subsidence over $-15 \mathrm{~mm} /$ year has also been observed surrounding the Guangzhou South Railway station. As the construction works for these lines were completed long before the CSK acquisitions (especially for line 3), it is likely that the deformation is caused by the weight of the buildings, given that the deformation areas are covered by dense buildings. 


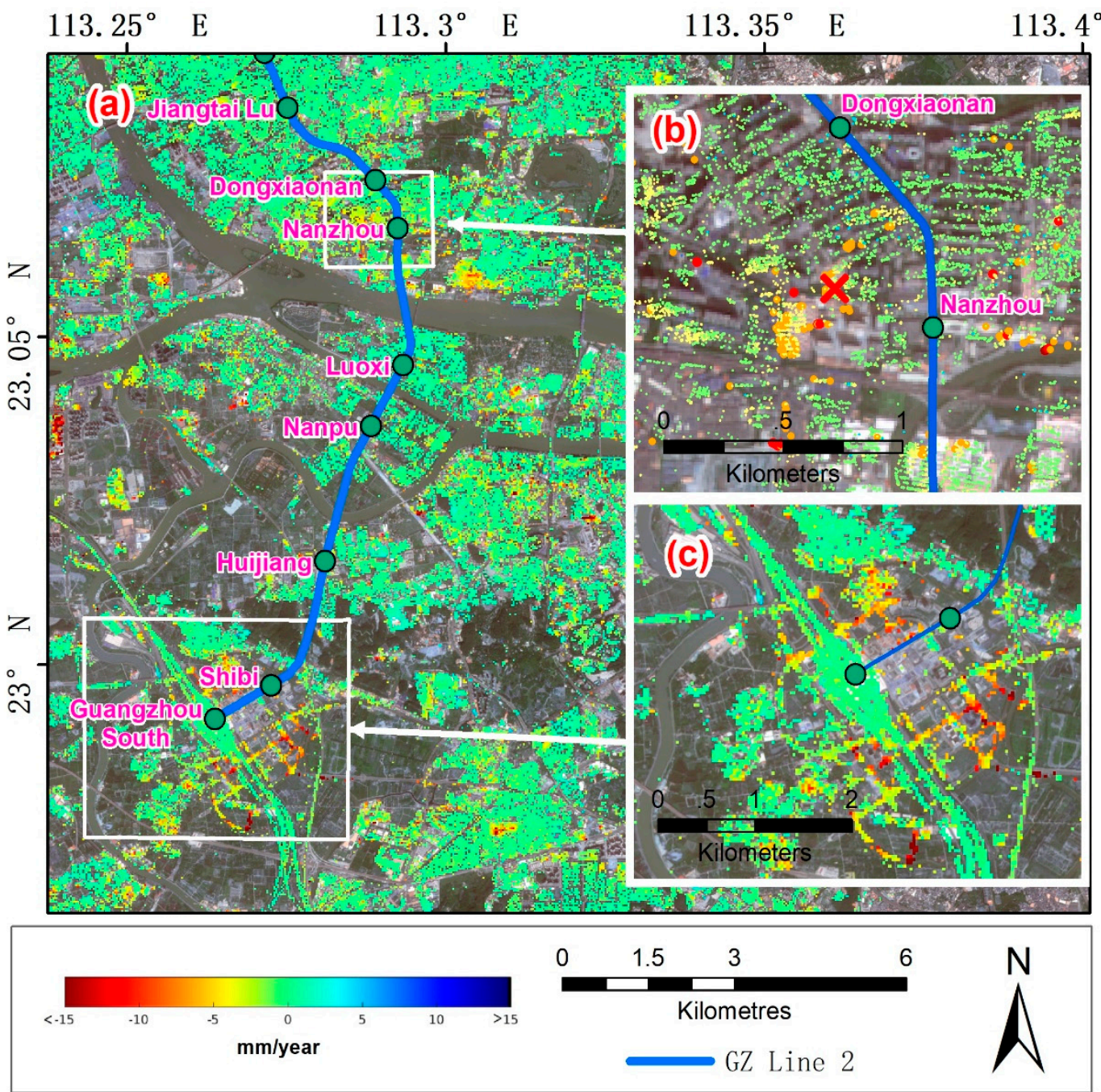

Figure 9. InSAR-measured displacement rate map between 2011 and 2017 over (a) south part of GZ Line 2; (b) Nanzhou station; (c) near Guangzhou South Railway station. The blue line represents the GZ Line 2 and the red cross in (b) represents the location of subsidence incident reported. The background images are the Sentinel-2 true colour images acquired on 1 November 2017.

Both GZ Lines 5 and 6 pass through an island. GZ Line 6 crosses the island in the north-south direction underground, while GZ Line 5 crosses the island through the elevated bridge in the east-west direction instead of using underground tunnel [44] (Figure 10). Large deformation with a peak subsidence rate over $-15 \mathrm{~mm}$ /year is observed at Jiaokou station (Figure 10b) after 2011. Since the GZ Line 5 between Jiaokou and Tanwei stations are connected by a bridge, the deformation is likely caused by concentrated urban development and heavy loading inducing sediment compaction (e.g., cyclic loading of trains). 


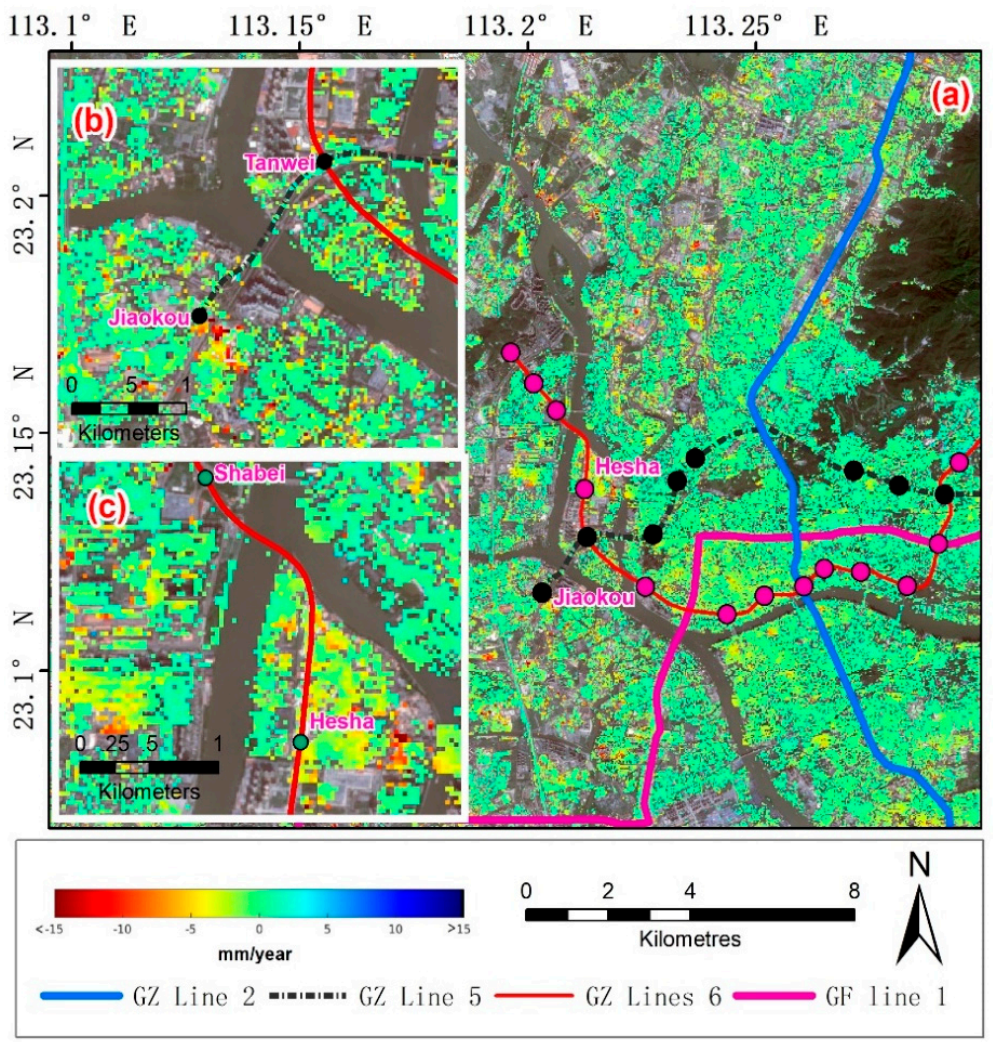

Figure 10. InSAR-measured displacement rate map (2011-2017) of (a) GZ Lines 2, 5, 6, and GuangFo (GF) Line 1; (b) Jiaokou and Tanwei stations; and (c) Hesha station. The blue, black, and purple lines represent GZ Lines 2 (north part), 5, and 6, respectively. The red line represents the GF Line 1 (east part).

We also analysed an area with varying displacement rates between 2011 and 2017 (highlighted in Figure 5). The region of interest is located near the Leigang station along the GuangFo subway line 1 (GF Line 1), where construction works ended in April 2010. Land settlement phenomenon has also been observed near the Leigang station (see Figures 6 and 11c). The underground excavation work for the first stage of GF Line 1 ended in April 2010, but the land near the station did not become stable until after mid 2012 (Figure 6), suggesting that the settlement duration at this area is roughly 1.8 years.

A large subsidence zone is also observed between the Dongping and Xincheng Dong stations, the last two stations of the GF Line 1 extension (Figure 11). The land displacement time series for the subsidence zone at the west of Xincheng Dong station is shown in Figure 12. It can be seen that the deformation patterns consist of 4 stages: (1) the land is stable until mid-2012; (2) rapid land deformation has been observed from late 2012 to early 2013; (3) the land becomes stable again until mid-2014; and (4) rapid land deformation has occurred again since mid-2014. The displacement time series seems to match the time of the construction works that began in 2012, hence, the deformation observed may be related to the construction work.

In this study we report on one of the limitations of InSAR for mapping subway construction-induced subsidence. Figure 13 shows the land deformation along the GZ Line 7, whose construction began in April 2013 and ended in February 2016. As shown in Figure 13, very limited measurement points can be obtained from the CSK dataset. This is because of the heavy development and construction along the GZ Line 7 at the same time of underground tunnel excavation. A typical example is the Nancun Wanbo station (Figure 13b). It can be observed that there are some measurement points with subsidence up to $-14 \mathrm{~mm}$ /year surrounding the station, but there is a lack of measurement points in the centre of the deformation zones (i.e., near the station). This issue is found for most stations along the GZ Line 7. 


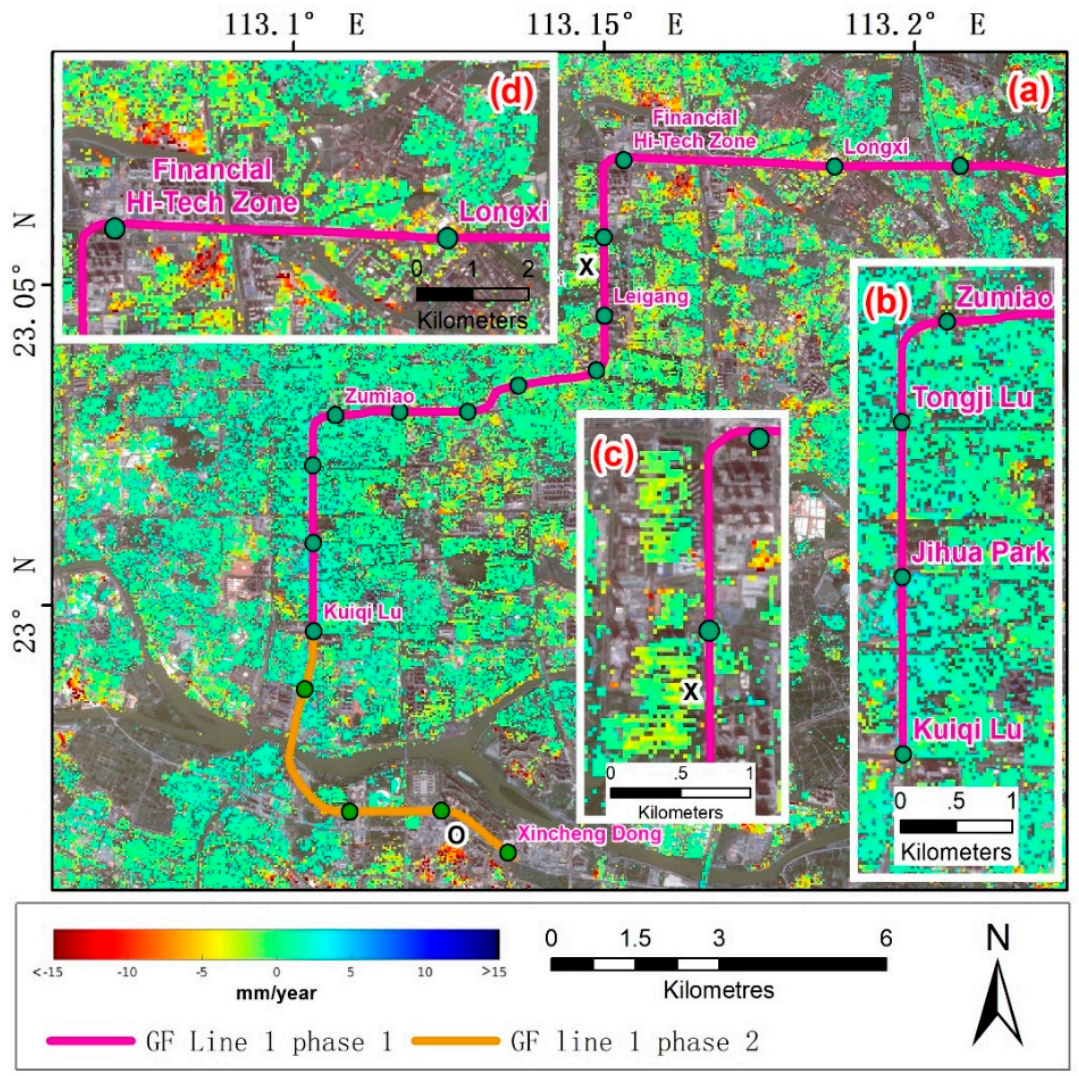

Figure 11. InSAR-measured displacement rate map between 2011 and 2017 over (a) GF Line 1 (west part); (b) the section from Zumiao station to Kuiqi Lu station; (c) the section from Financial Hi-Tech Zone station to Leigang station; and (d) the section from Longxi station to Financial Hi-Tech Zone station. The purple line represents the GF Line 1 phase 1 and the orange line represents the GF line 1 phase 2 (i.e., extension of phase 1).

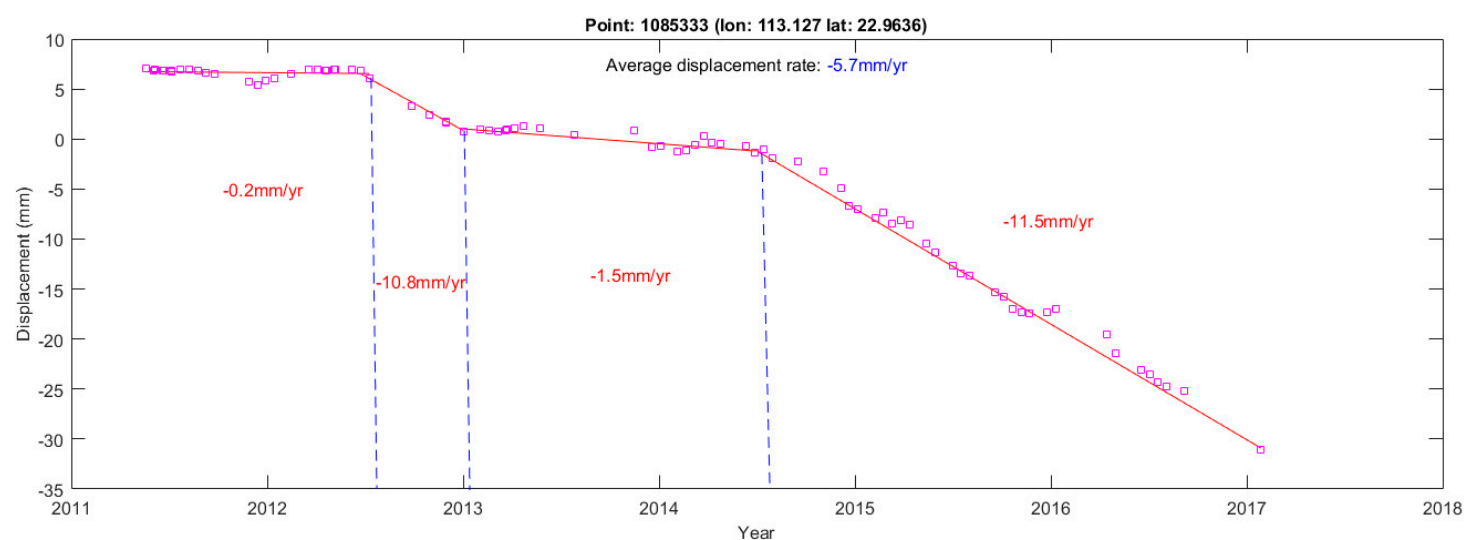

Figure 12. InSAR-measured displacement series near Dongping and Xincheng Dong stations (point ' $\mathrm{O}$ ' in Figure 11). 


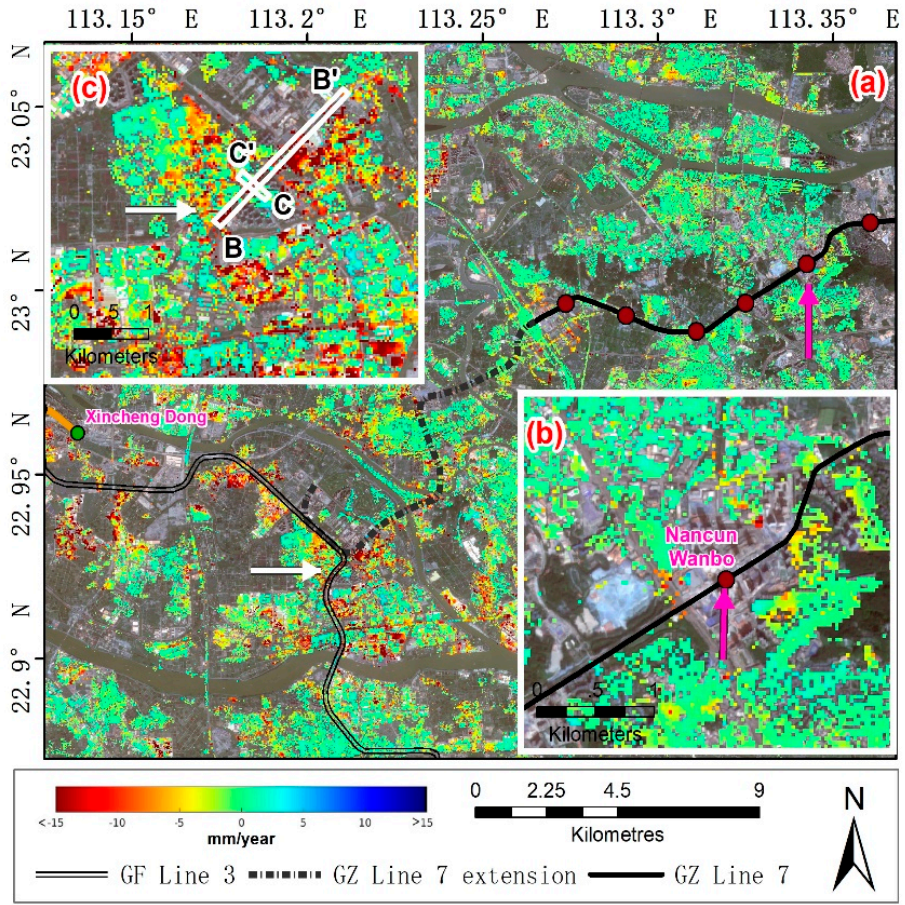

Figure 13. InSAR-measured displacement rate map (2011-2017) of (a) GZ Line 7, GZ Line 7 extension (under construction) and GF Line 3 (under construction); (b) Nancun Wanbo station; and (c) two subway lines under construction. The background images are the Sentinel-2 true colour images acquired on 1 November 2017. The white boxes in (c) indicate the location of the profile lines B-B' and C-C'.

\subsection{Identification of Potential Areas of Risk}

The X-band CSK data, with much finer spatial resolution than C- and L-band satellite data, makes it possible for high-resolution land subsidence monitoring [22]. High-density measurement data, obtained from the CSK data, is very useful for studying the deformation of the transport infrastructures, e.g., highway, road, railway, and subway. The deformation information obtained is important to identify the possible risk areas.

A massive sinkhole of about $30 \mathrm{~m}$ wide and $6 \mathrm{~m}$ deep, occurred on 7 February 2018 in Foshan [45] and has been analysed in this work. The characteristics of the subsidence signal observed may be useful for identifying areas at risk of sinkhole collapse in the future. The sinkhole collapse occurred near the Jihua Xi road and Foshan No. 1 Ring Road Bridge intersection, and caused at least eight casualties, three lost and nine injured people. It is likely that the sinkhole collapse was caused by a water leak in a construction site of the subway station (GF line 2). A broken underground pipe or a change in ground water flow paths may have been the reason for water leaking into the underground tunnel. Figure 14 shows the field investigation photo at the sinkhole and the displacement rate map over the region. The longitudinal subsidence profile (A- $\mathrm{A}^{\prime}$ in Figure 14) near the location of incident on Jihua $\mathrm{Xi}$ road is shown in Figure 15. It can be seen that the subsidence rate along the profile is over $-8 \mathrm{~mm} /$ year. Interestingly, the subsidence rate increases rapidly east of the sinkhole location, where the peak subsidence rate is over $-30 \mathrm{~mm} /$ year. The explanation for this pattern is uncertain, but it is possibly due to the hinged or sealed failure of the shield tail (at the location of the incident). The InSAR-measured displacement series (2011-2017) near the subsidence incident is shown in Figure 16. Continuous subsidence with a rate of about $-9 \mathrm{~mm}$ /year has been observed since 2011, which is long before the construction work for GF line 2 started (i.e., June 2014). Therefore, the subsidence observed since 2011 at the Jinhua Xi road is likely caused by other factors, e.g., surface loading. Heavy loading of the ground can be a factor contributing to sinkhole collapse together with damage to the pavement and/or the pipes buried underneath [46]. Moreover, surface load in a 
saturated ground can push the groundwater flow into an underground tunnel [47]. The evolution of land deformation near the time of the collapse is useful to improve the understanding of the causes of the sinkhole, but unfortunately the CSK data acquired after 2017 are not available to us. Nevertheless, based on the observations from the Foshan sinkhole, it is reasonable to expect that other locations with similar conditions are at risk of sinkhole formation.

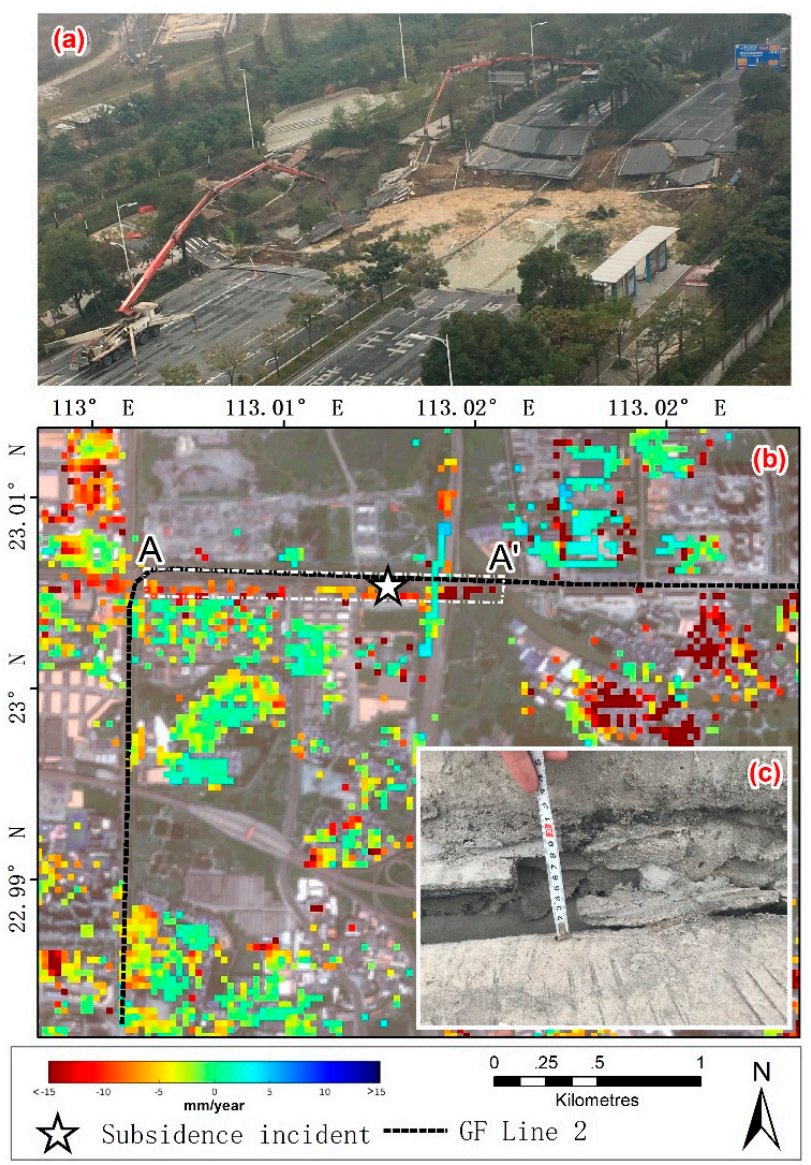

Figure 14. (a) The field investigation photo for the subsidence incident; (b) the InSAR-measured displacement rate map (2011-2017) of GZ Line 2 (under construction); and (c) the field investigation photo near the location of the incident. The white star represents the location of the Jihua Xi road subsidence incident. The box with white broken line in $(\mathbf{b})$ indicates the location of the profile lines $\mathrm{A}-\mathrm{A}^{\prime}$.

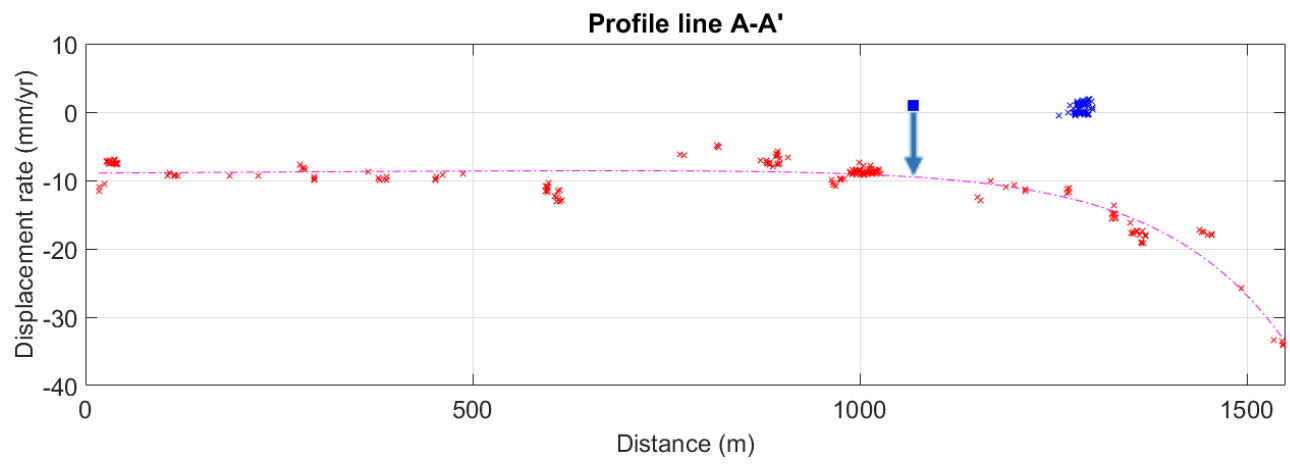

Figure 15. The longitudinal subsidence profile $\left(\mathrm{A}-\mathrm{A}^{\prime}\right)$ near the subsidence incident on Jihua Xi road (the white star in Figure 14). The blue square indicates the location of the incident. The red crosses represent the subsidence rate along Jihua Xi road. The blue crosses represent the subsidence rate at the Foshan No. 1 Ring Road Bridge. 


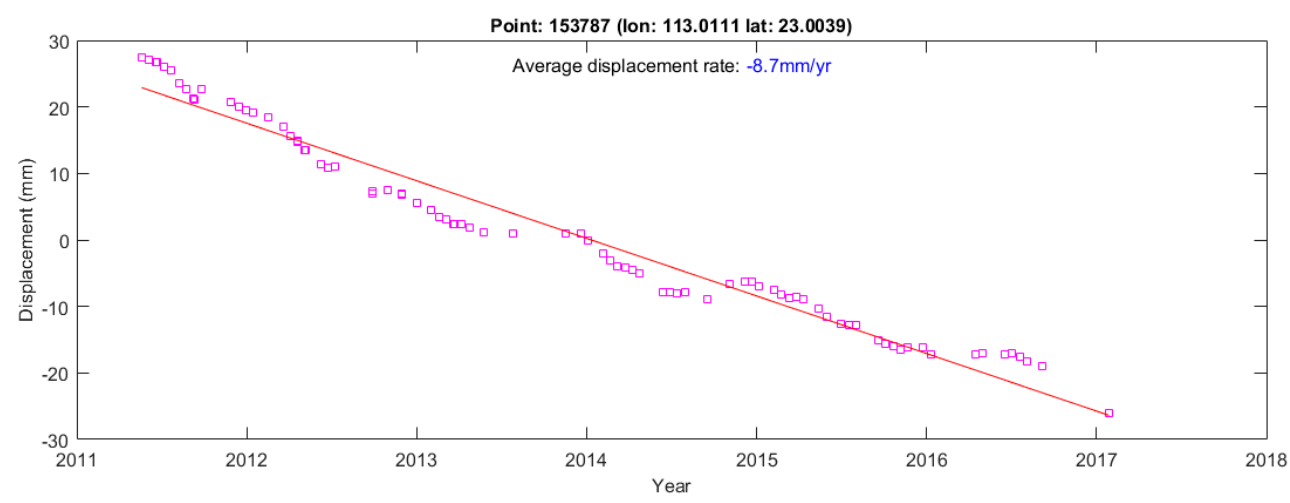

Figure 16. InSAR-measured displacement series near at the location of Jihua road subsidence incident (the white star in Figure 14).

Several areas that are potentially at risk are identified based on the subsidence characteristic for GF Line 2. For example, the two subway lines, GZ Line 7 extension and GF Line 3, which pass through the Beijiao Township were under construction as the time the manuscript was prepared (construction began in mid to late 2016). It can be seen in Figure 13a that both subway lines pass through a number of deformation zones where some of them are deforming with a rate of over $-20 \mathrm{~mm} /$ year. The sections of two subway lines that follow the National Highway Beijing Zhuhai line (highlighted by the white arrow in Figure 13c) are experiencing rapid deformation. These are similar to the case of GF Line 2, where continuous subsidence occurred before the subway construction started. Hence, surface loading from highway vehicles is expected to be one of the main factors causing subsidence. The profile lines in longitudinal $\left(B-B^{\prime}\right)$ and transverse directions $\left(C-C^{\prime}\right)$ near Nan Yuan road on the National Highway Beijing Zhuhai line (white boxes in Figure 13c) are shown in Figures 17 and 18. The observed subsidence rate along the longitudinal direction is over $-10 \mathrm{~mm} /$ year in most area with a peak subsidence approaching $-30 \mathrm{~mm} /$ year. In addition, the area affected by subsidence along the transverse direction is roughly $200 \mathrm{~m}$ wide. Although similar subsidence characteristics were reported between these subway lines, there are many more high-rise buildings near Nan Yuan road. Therefore, greater loss is expected if a sinkhole would form in these areas. Continuous monitoring in this area is, therefore, very important to minimise the risk of ground collapse during or after the underground excavation work.

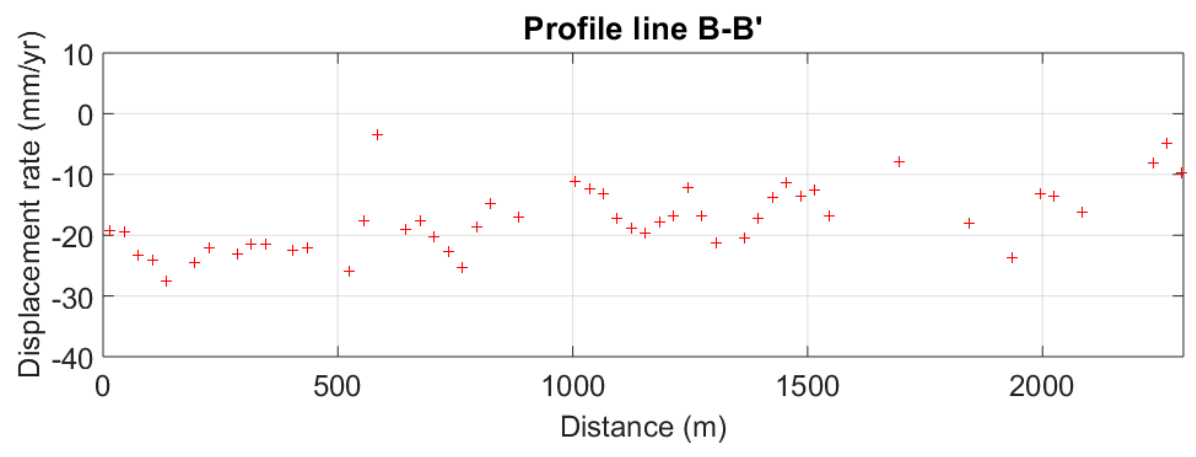

Figure 17. Longitudinal subsidence profile near Nan Yuan road on the National Highway Beijing Zhuhai line (B-B' in Figure 13c). 


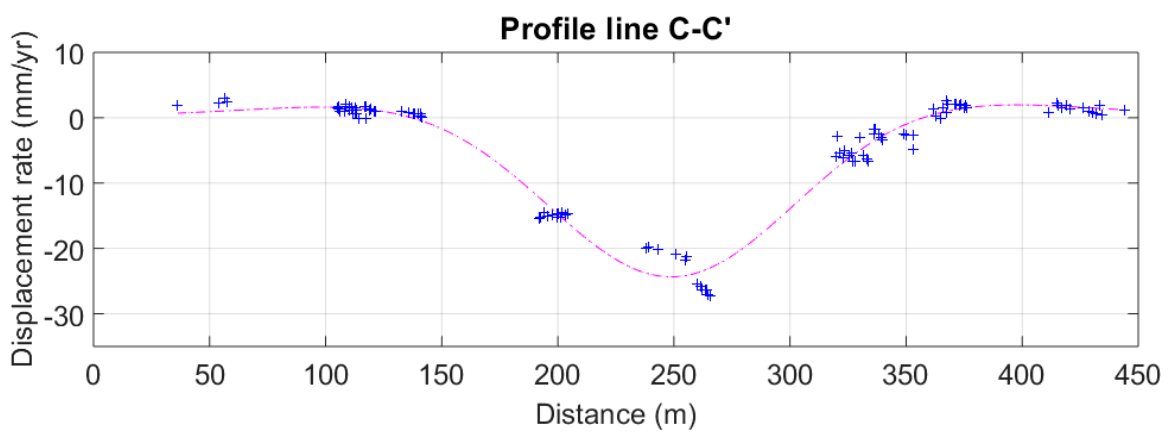

Figure 18. Transverse subsidence profile near Nan Yuan road on the National Highway Beijing Zhuhai line $\left(C-C^{\prime}\right.$ in Figure $\left.13 c\right)$.

\subsection{TS-InSAR Results in Different Land Use Types}

The relationship between the TS-InSAR measurements and different land use types in Guangzhou is analysed in this work. The land use map in Guangzhou City is shown in Figure 19. The land use classification data is digitised from the 2015 Guangzhou land use map (published by Guangzhou land resources and the Planning Committee). The TS-InSAR measurement points corresponding to each land use types (and sub-types) are searched and identified. The statistics of the TS-InSAR measurements at different land use types (and sub-types) are computed (Table 1). Although slightly larger subsidence rates are observed in land use type such as woodland, cropland, and grassland, the difference between their subsidence rates and those from other land use types are smaller than 1 sigma (Table 1). Therefore, we conclude that no clear relationship between the land subsidence and the land use types exists in Guangzhou, mainly because the subsidence here is mainly at the local scale.

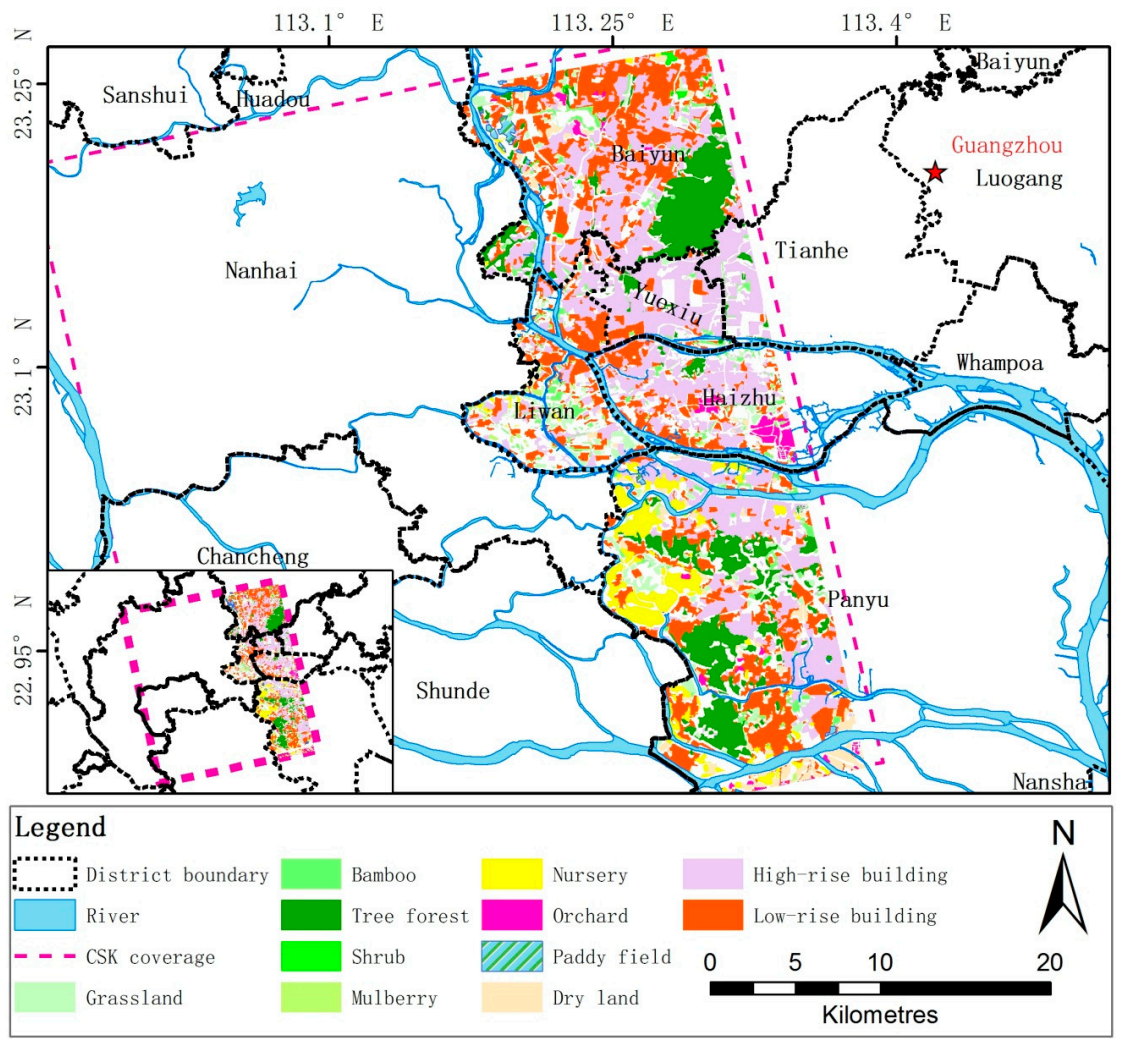

Figure 19. Land use map in the study area of Guangzhou City. 
Table 1. Statistics of TS-InSAR measurements for different land use types.

\begin{tabular}{|c|c|c|c|c|c|c|c|c|c|}
\hline $\begin{array}{l}\text { Land } \\
\text { Use Type }\end{array}$ & $\begin{array}{l}\text { Land Use } \\
\text { Sub-Type }\end{array}$ & PS + DS & PS * & DS ** & Area $\left(\mathbf{k m}^{2}\right)$ & $\begin{array}{l}\text { PS Density } \\
\left(\text { point } / \mathbf{k m}^{2}\right)\end{array}$ & $\begin{array}{l}\text { DS Density } \\
\left(\text { point } / \mathbf{k m}^{2}\right)\end{array}$ & $\begin{array}{l}\text { Mean Subsidence } \\
\text { Rate (mm/year) }\end{array}$ & $\begin{array}{l}\text { Subsidence Rate Standard } \\
\text { Deviations ( } \mathrm{mm} / \text { year) }\end{array}$ \\
\hline \multirow[t]{3}{*}{ Building } & & $1,052,854$ & 48,358 & $1,004,496$ & 253.6 & 190.7 & 3961.7 & -0.2 & 1.8 \\
\hline & Low-rise building & 402,511 & 18,611 & 383,900 & 115.7 & 160.8 & 3317.4 & -0.5 & 2.1 \\
\hline & High-rise building & 650,343 & 29,747 & 620,596 & 137.8 & 215.8 & 4502.7 & -0 & 1.5 \\
\hline \multirow[t]{4}{*}{ Woodland } & & 24,378 & 866 & 23,512 & 28.4 & 30.5 & 827.9 & -0.8 & 2.7 \\
\hline & Orchard & 2088 & 86 & 2002 & 5.4 & 15.9 & 370.7 & -1.6 & 2.8 \\
\hline & Nursery land & 21,400 & 752 & 20,648 & 21.7 & 34.7 & 952.3 & -0.7 & 2.7 \\
\hline & Mulberry farm & 890 & 28 & 862 & 1.3 & 21.2 & 653.8 & -1.5 & 3.9 \\
\hline \multirow[t]{4}{*}{ Forest } & & 78,847 & 3992 & 74,855 & 71.7 & 55.7 & 1043.5 & -0.4 & 1.9 \\
\hline & Bamboo & 39,271 & 1928 & 37,343 & 14.5 & 132.7 & 2569.6 & -0.7 & 2.1 \\
\hline & Shrub & 1026 & 44 & 982 & 1.4 & 31.2 & 697.3 & -0.7 & 2.4 \\
\hline & Tree Forest & 38,550 & 2020 & 36,530 & 55.8 & 36.2 & 654.8 & -0.1 & 1.7 \\
\hline \multirow[t]{3}{*}{ Crop land } & & 8949 & 518 & 8431 & 14.3 & 36.2 & 590.0 & -1 & 2.9 \\
\hline & Paddy field & 560 & 8 & 552 & 1.8 & 4.5 & 307.7 & -2 & 3.6 \\
\hline & Dry land & 8389 & 510 & 7879 & 12.5 & 40.8 & 630.5 & -1 & 2.8 \\
\hline Grassland & & 23,992 & 661 & 23,331 & 12.4 & 53.2 & 1877.5 & -1.4 & 3.6 \\
\hline
\end{tabular}

${ }^{*}$ TS-InSAR measurement points (final product) with $\mathrm{D}_{\mathrm{A}}<0.25$ are considered as PS. ${ }^{* *}$ DS points are the TS-InSAR measurement points (final product) that are not considered as PS. 
The density of PS and DS points in the different land use types are reported in Table 1 . These values agree well with the theory, whereby the highest density of PS and DS correspond to areas with buildings, with $190.7 \mathrm{PS} / \mathrm{km}^{2}$ and $3961.7 \mathrm{DS} / \mathrm{km}^{2}$. The density of measurement points observed is slightly higher for high-rise than for low-rise buildings. This is because low-rise buildings are often located in the sparsely-urbanised areas (i.e., fewer buildings) with low population density. The land use types of woodland and cropland have the lowest density points because of crop harvesting and/or re-growth, leading to strong decorrelation. In particular, the paddy fields, a special type of cropland, and orchard fields, a type of woodland, have the lowest point density amongst all land use types. Dry land, another type of cropland, with extremely low moisture content in the soil, appears to have approximately 10 times higher density of PS and DS than the paddy field. It is observed that the land use types of forest and grassland have moderate point densities, likely because they are more stable in time compared to the woodland and cropland. However, very high deviation in point density has been observed over the forest. The point density of bamboo, with $132.7 \mathrm{PS} / \mathrm{km}^{2}$ and $2569.6 \mathrm{DS} / \mathrm{km}^{2}$, is just behind the building counterpart. On the other hand, the point densities of shrub and tree forest are at similar levels as the woodland and cropland. Most areas of the bamboo land use type in Guangzhou has a sparse to intermediate canopy with sparse understory. Since the bamboo does not have branches like other trees do, it is likely that bamboo trunk behaves as a corner reflector. On the other hand, a closed canopy and/or dense understory are expected for most areas in shrub and tree forests. Since X-band signal is unlikely to be able to penetrate through the canopy, therefore, strong temporal decorrelation (due to volume scattering) is expected at these land use types.

\section{Conclusions}

We characterised the surface deformation in Guangzhou and Foshan using time-series analysis of CSK data acquired between May 2011 and January 2017. A total of 86 CSK images have been processed using the TS-InSAR analysis technique to explore the evolution of the surface displacements. The result shows that the displacement rates in these cities are between $-35 \mathrm{~mm} /$ year to $10 \mathrm{~mm} /$ year. We analysed two independent TS-InSAR datasets, using the data acquired between 2011 and 2013, and the data from 2013 to 2017, respectively, to investigate the temporal behaviour of the land subsidence phenomena. The results indicate that linear trends of displacement are appropriate in most areas. The comparison with the ENVISAT and levelling data show that the displacement measurements generally agree with each other well, suggesting that most areas in the region are stable.

A few regional scales', and many local scales', deformation signals have been identified in the cities. The deformation mainly consists of subsidence as a result of human activities, like excessive groundwater extraction and underground tunnel construction. A number of possible groundwater subsidence zones have been identified mostly in agricultural and industrial areas. The spatial extent of groundwater subsidence found in Guangzhou and Foshan are within a few kilometres, which is because most groundwater was extracted from shallow $5 \mathrm{~km}$ depth reservoirs.

Many subsidence signals caused by underground excavations, as identified in previous studies have now become stable. However, several new subsidence areas have been identified along the GZ Line 7, the extension of the GF Line 1, and GZ Line 6 that were not identified by previous studies. One of the main limitations for using InSAR to measure the subsidence in areas of subway construction is due to the fact that heavy development and construction on the ground often occurs along the subway line during the same period of tunnelling construction. Hence, it can be difficult to obtain the comprehensive subsidence map because of the lack of measurement points, especially when the districts are developed following the construction of the subway line.

A sinkhole collapse occurred on 7 February 2018 in Foshan. Potential areas at risk of sinkhole collapse have been identified based on the study of the subsidence signal preceding the collapse in Foshan. We find that that the subsidence rate along the highway nearby the sinkhole was over $-8 \mathrm{~mm}$ /year. We argue that the main contribution to this subsidence is the heavy loading (e.g., highway vehicles) on the road rather than underground tunnel excavation. Several areas 
that are potentially at risk of sinkhole collapse have been identified, but further investigation is necessary to improve the understanding of loading-induced subsidence, groundwater subsidence, and underground excavation induced subsidence in these areas to avoid ground collapse incidents during or after the underground construction work.

The TS-InSAR measurement at different land use types in Guangzhou has been analysed. No clear relationship between the land subsidence and the land use types has been observed. Therefore, it is believed that the subsidence phenomena in Guangzhou are mainly localised. Moreover, quantitative evaluation of the TS-InSAR measurement point density at different land use types is conducted, showing that the highest density point is found for the land use type of buildings, followed by the grassland and forest with sparse canopy and, finally, the plantation and forest with dense canopy. The data obtained here provide useful information for helping future TS-InSAR studies with X-band data.

Author Contributions: A.H.-M.N. and H.W. conceived the research work; A.H.-M.N. wrote the first draft of the paper; A.H.-M.N. and H.W. analysed the data; Y.D., W.C. and K.Z. contributed to the experiment implementation and results interpretation; and A.H.-M.N., H.W., C.P., Z.D. and L.G. contributed to paper writing and revision.

Funding: This research was funded by Natural Science Foundation of Guangdong Province (grant number 2015A030313489), Guangzhou Science and Technology Program (grant number 201510010062) and Guangdong University of Technology startup research grant (grant no. 50010102).

Acknowledgments: The authors thank ASI for providing the COSMO-SkyMed data through an open call for science project (ID 453) and ESA for providing the Sentinel-2 data.

Conflicts of Interest: The authors declare no conflict of interest.

\section{References}

1. Syvitski, J.P.M.; Kettner, A.J.; Overeem, I.; Hutton, E.W.H.; Hannon, M.T.; Brakenridge, G.R.; Day, J.; Vörösmarty, C.; Saito, Y.; Giosan, L.; et al. Sinking deltas due to human activities. Nat. Geosci. 2009, 2, 681-686. [CrossRef]

2. Bakr, M. Influence of groundwater management on land subsidence in Deltas. Water Resour. Manag. 2015, 29, 1541-1555. [CrossRef]

3. Wang, H.; Wright, T.J.; Yu, Y.; Lin, H.; Jiang, L.; Li, C.; Qiu, G. InSAR reveals coastal subsidence in the Pearl River Delta, China. Geophys. J. Int. 2012, 191, 1119-1128. [CrossRef]

4. Zhao, Q.; Lin, H.; Jiang, L.; Chen, F.; Cheng, S. A study of ground deformation in the Guangzhou urban area with Persistent Scatterer Interferometry. Sensors 2009, 9, 503-518. [CrossRef] [PubMed]

5. Wang, H.; Feng, G.; Xu, B.; Yu, Y.; Li, Z.; Du, Y.; Zhu, J. Deriving spatio-temporal development of ground subsidence due to subway construction and operation in delta regions with PS-InSAR data: A case study in Guangzhou, China. Remote Sens. 2017, 9, 1004. [CrossRef]

6. Chen, F.; Lin, H.; Zhang, Y.; Lu, Z. Ground subsidence geo-hazards induced by rapid urbanization: Implications from InSAR observation and geological analysis. Nat. Hazards Earth Syst. Sci. 2012, 12, 935-942. [CrossRef]

7. Huang, H.; Chen, X.; Zhu, Z.; Xie, Y.; Liu, L.; Wang, X.; Wang, X.; Liu, K. The changing pattern of urban flooding in Guangzhou, China. Sci. Total Environ. 2018, 622-623, 394-401. [CrossRef] [PubMed]

8. Lyu, H.-M.; Wang, G.-F.; Shen, J.; Lu, L.-H.; Wang, G.-Q. Analysis and GIS mapping of flooding hazards on 10 May 2016, Guangzhou, China. Water 2016, 8, 447. [CrossRef]

9. Strozzi, T.; Delaloye, R.; Poffet, D.; Hansmann, J.; Loew, S. Surface subsidence and uplift above a headrace tunnel in metamorphic basement rocks of the Swiss Alps as detected by satellite SAR interferometry. Remote Sens. Environ. 2011, 115, 1353-1360. [CrossRef]

10. Milillo, P.; Giardina, G.; DeJong, M.; Perissin, D.; Milillo, G. Multi-Temporal InSAR Structural Damage Assessment: The London Crossrail Case Study. Remote Sens. 2018, 10, 287. [CrossRef]

11. Robles, J.G.; Black, M.; Gomar, B.S. Correlation Study between In-Situ Auscultation and Satellite Interferometry for the Assessment of Nonlinear Ground Motion on Crosrail London; Crossrail Learning Legacy Report: London, UK, 2016. 
12. Chaussard, E.; Milillo, P.; Burgmann, R.; Perissin, D.; Fielding, J.F.; Baker, B. Remote Sensing of Ground Deformation for Monitoring Groundwater Management Practices: Application to the Santa Clara Valley During the 2012-2015 California Drought. J. Geophys. Res. Solid Earth 2017, 122, 8566-8582. [CrossRef]

13. Bonì, R.; Cigna, F.; Bricker, S.; Meisina, C.; McCormack, H. Characterisation of hydraulic head changes and aquifer properties in the London Basin using Persistent Scatterer Interferometry ground motion data. J. Hydrol. 2016, 540, 835-849. [CrossRef]

14. Ferretti, A.; Fumagalli, A.; Novali, F.; Prati, C.; Rocca, F.; Rucci, A. A new algorithm for processing Interferometric Data-Stacks: SqueeSAR. IEEE Trans. Geosci. Remote Sens. 2011, 49, 3460-3470. [CrossRef]

15. Ferretti, A.; Prati, C.; Rocca, F. Permanent Scatterers in SAR interferometry. IEEE Trans. Geosci. Remote Sens. 2001, 39, 8-20. [CrossRef]

16. Ferretti, A.; Prati, C.; Rocca, F. Nonlinear subsidence rate estimation using Permanent Scatterers in Differential SAR Interferometry. IEEE Trans. Geosci. Remote Sens. 2000, 38, 2202-2212. [CrossRef]

17. Beradino, P.; Fornaro, G.; Lanari, R.; Sansosti, E. A new algorithm for surface deformation monitoring based on Small Baseline Differential SAR Interferograms. IEEE Trans. Geosci. Remote Sens. 2002, 40, 2375-2383. [CrossRef]

18. Kampes, B.M. Radar Interferometry: Persistent Scatterer Technique, 1st ed.; Springer: Dordrecht, The Netherland, 2006; p. 211.

19. Du, Z.; Ge, L.; Ng, A.H.-M.; Xiaojing, L.; Li, L. Mapping land subsidence over the eastern Beijing city using Satellite Radar Interferometry. Int. J. Digit. Earth 2017, 1-16. [CrossRef]

20. Ng, A.H.-M.; Ge, L.; Li, X. Assessments of land subsidence in the Gippsland Basin of Australia using ALOS PALSAR data. Remote Sens. Environ. 2015, 159, 86-101. [CrossRef]

21. Ge, L.; Ng, A.H.-M.; Li, X.; Abidin, H.Z.; Gumilar, I. Land subsidence characteristics of Bandung Basin as revealed by ENVISAT ASAR and ALOS PALSAR Interferometry. Remote Sens. Environ. 2014, 154, 46-60. [CrossRef]

22. Perissin, D.; Wang, Z.; Lin, H. Shanghai subway tunnels and highways monitoring through Cosmo-SkyMed Persistent Scatterers. ISPRS J. Photogramm. Remote Sens. 2012, 73, 58-67. [CrossRef]

23. Ng, A.H.-M.; Ge, L.; Zhang, K.; Li, X. Estimating horizontal and vertical movement due to underground mining using ALOS PALSAR. Eng. Geol. 2012, 143-144, 18-27. [CrossRef]

24. Chen, F.; Lin, H.; Zhou, W.; Hong, T.; Wang, G. Surface deformation detected by ALOS PALSAR Small Baseline SAR Interferometry over permafrost environment of Beiluhe section, Tibet Plateau, China. Remote Sens Environ. 2013, 138, 10-18. [CrossRef]

25. Zhao, Q.; Lin, H.; Jiang, L. Ground deformation monitoring in Pearl River Delta region with Stacking D-InSAR technique. In Geoinformatics 2008 and Joint Conference on GIS and Built Environment: Monitoring and Assessment of Natural Resources and Environments; International Society for Optics and Photonics: Bellingham, WA, USA, 2008; Volume 7145.

26. Wang, H.; Yu, Y.-P.; Jiang, L.L. Monitoring land subsidence in Guangzhou and Foshan using InSAR. Sci. Surv. Mapp. 2014, 39, 66-71.

27. Nof, R.N.; Baer, G.; Ziv, A.; Raz, E.; Atzori, S.; Salvi, S. Sinkhole precursors along the Dead Sea, Israel, revealed by SAR interferometry. Geology 2013, 41, 1019-1022. [CrossRef]

28. Chang, L.; Hanssen, R.F. Detection of cavity migration and sinkhole risk using Radar Interferometric time series. Remote Sens. Environ. 2014, 147, 56-64. [CrossRef]

29. Ren, D.-J.; Shen, S.-L.; Cheng, W.-C.; Zhang, N.; Wang, Z.-F. Geological formation and geo-hazards during subway construction in Guangzhou. Environ. Earth Sci. 2016, 75, 934. [CrossRef]

30. Chen, M.; Shen, S.L.; Wu, H.N.; Wang, Z.F.; Horpibulsuk, S. Geotechnical characteristics of weathered granitic gneiss with geo-hazards investigation of pit excavation in Guangzhou, China. Bull. Eng. Geol. Environ. 2017, 76, 681-694. [CrossRef]

31. Ng, A.H.-M.; Ge, L.; Li, X.; Zhang, K. Monitoring ground deformation in Beijing, China with Persistent Scatterer SAR Interferometry. J. Geod. 2012, 86, 375-392. [CrossRef]

32. Massonnet, D.; Rossi, M.; Carmona, C.; Adragna, F.; Peltzer, G.; Feigl, K.; Rabaute, T. The displacement field of the Landers Earthquake mapped by Radar Interferometry. Nature 1993, 364, 138-142. [CrossRef]

33. Ge, L.; Ng, A.H.-M.; Wang, H.; Rizos, C. Crustal deformation in Australia measured by Satellite Radar Interferometry using ALOS/PALSAR imagery. J. Appl. Geod. 2009, 3, 47-53. [CrossRef] 
34. Rodriguez, E.; Morris, C.S.; Belz, J.E.; Chapin, E.C.; Martin, J.M.; Daffer, W.; Hensley, S. An Assessment of the SRTM Topographic Products; Report No. JPL D-31639; Jet Propulsion Laboratory: Pasadena, CA, USA, 2005.

35. Guarnieri, A.M.; Tebaldini, S. On the exploitation of target statistics for SAR Interferometry applications. IEEE Trans. Geosci. Remote Sens. 2008, 46, 3436-3443. [CrossRef]

36. Colesanti, C.; Ferretti, A.; Novali, F.; Prati, C.; Rocca, F. SAR monitoring of progressive and seasonal ground deformation using the Permanent Scatterers technique. IEEE Trans. Geosci. Remote Sens. 2003, 41, 1685-1701. [CrossRef]

37. Ng, A.H.-M.; Ge, L.; Li, X.; Abidin, H.Z.; Andreas, H.; Zhang, K. Mapping land subsidence in the Jakarta city, Indonesia using Persistent Scatterer Interferometry (PSI) technique with ALOS PALSAR. Int. J. Appl. Earth Obs. Geoinf. 2012, 18, 232-242. [CrossRef]

38. Fialko, Y.; Simons, M.; Agnew, D. The complete (3-D) surface displacement field in the epicentral area of the 1999 Mw 7.1 Hector Mine Earthquake, California, from space geodetic observations. Geophys. Res. Lett. 2001, 28, 3063-3066. [CrossRef]

39. $\mathrm{Xu}, \mathrm{M}$. Foshan Groundwater Resources to be Thoroughly. Guangzhou Daily, 11 January 2006. (In Chinese)

40. Zhang, Y.; Gong, H.; Gu, Z.; Wang, R.; Li, X.; Zhao, W. Characterization of land subsidence induced by groundwater withdrawals in the plain of Beijing city, China. Hydrogeol. J. 2014, 22, 397-409. [CrossRef]

41. Zhu, L.; Gong, H.; Li, X.; Wang, R.; Chen, B.; Dai, Z.; Teatini, P. Land subsidence due to groundwater withdrawal in the Northern Beijing Plain, China. Eng. Geol. 2015, 193, 243-255. [CrossRef]

42. Wangsaatmaja, S.; Sutadian, A.D.; Prasetiati, M.N. A review of groundwater issues in the Bandung Basin, Indonesia: Management and recommendations. Int. Rev. Environ. Strateg. 2006, 6, 425-441.

43. Luo, H.; Li, Y. Residents are Worried about Frequent Cracks Found in Half of the Residential Buidlings in an Area of Haizhu. Guangzhou News Express, 30 March 2016. (In Chinese)

44. Liu, C. Engineering geologic problems of Guangzhou Metro Line 5 and the countermeasures. Urban Mass Transit 2006, 7, 37-39.

45. AFP. Massive Sinkhole the Size of Two Basketball Courts Swallows Eight-Lane Road in a Chinese City, Leaving at Least Eight Dead. Daily Mail, 8 February 2018.

46. Gong, X.-N.; Sun, Z.-J.; Yu, J.-L. Analysis of displacement of adjacent buried pipeline caused by ground surcharge. Rock Soil Mech. 2015, 36, 305-310.

47. Prassetyo, S.H.; Gutierrez, M. Effect of surface loading on the hydro-mechanical response of a tunnel in saturated ground. Undergr. Sp. 2016, 1, 1-19. [CrossRef] 